\title{
The human imperative of stabilizing global climate change at $1.5^{\circ} \mathrm{C}$.
}

Authors:

O. Hoegh-Guldberg ${ }^{1,2}$, D. Jacob ${ }^{3}$, M. Taylor ${ }^{4}$, T. Guillén Bolaños ${ }^{3}$, M. Bindi' ${ }^{5}$, S. Brown ${ }^{6,7}$, I. A. Camilloni $^{8}$, A. Diedhiou ${ }^{9}$, R. Djalante ${ }^{10,11}$, K. Ebi ${ }^{12}$, F. Engelbrecht ${ }^{13}$, J. Guiot ${ }^{14}$, Y. Hijioka ${ }^{15}$, S. Mehrotra $^{16}$, C. W. Hope ${ }^{17}$, A. J. Payne ${ }^{18}$, H-O Pörtner ${ }^{19}$, S. I. Seneviratne ${ }^{20}$, A. Thomas ${ }^{21,22}$, R. Warren ${ }^{23}$, G. Zhou ${ }^{24}$.

\section{Affiliations:}

1. Global Change Institute, University of Queensland, St Lucia 4072 QLD Australia

2. School of Biological Sciences, University of Queensland, St Lucia 4072 QLD, Australia

3. Climate Service Center Germany (GERICS), Helmholtz-Zentrum Geesthacht, Hamburg, Germany

4. Department of Physics, University of the West Indies, Kingston, Jamaica

5. Department of Agriculture, Food, Environment and Forestry (DAGRI) -University of Florence, Piazzale delle Cascine 18, 50144 Italy

6. Faculty of Engineering and Physical Sciences, University of Southampton, Boldrewood Innovation Campus, Burgress Road, Southampton. SO16 7QF, UK

7. Department of Life and Environmental Sciences, Faculty of Science and Technology, Bournemouth University, Fern Barrow, Poole, Dorset, BH12 5BB, UK

8. Centro de Investigaciones del Mar y la Atmósfera (UBA-CONICET), UMI-IFAECI/CNRS, and Departamento de Ciencias de la Atmósfera y los Océanos (FCEN, UBA), Buenos Aires, Argentina

9. Université Grenoble Alpes, French National Research Institute for Sustainable Development (IRD), CNRS, Grenoble INP, IGE, F-38000 Grenoble, France United Nations University 10. United Nations University - Institute for the Advanced Study of Sustainability (UNU-IAS), Tokyo, Japan

11. Halu Oleo University, Kendari, South East Sulawesi, Indonesia

12. Center for Health and the Global Environment, University of Washington, Seattle WA, USA 13. Global Change Institute, University of the Witwatersrand, Johannesburg 2193, South Africa 
33 14. Aix Marseille University, CNRS, IRD, INRA, College de France, CEREGE, Aix-en34 Provence, France

35 15. Center for Climate Change Adaptation, National Institute for Environmental Studies, 16-2,

36 Onogawa, Tsukuba, Ibaraki, 305-8506, Japan

37 16. The World Bank, Washington DC, United States.

38 17. Cambridge Judge Business School, University of Cambridge, Cambridge, UK

39 18. University of Bristol, Bristol, UK

40 19. Alfred Wegener Institute, Helmholtz Centre for Polar and Marine Research, Bremerhaven, 41 Germany

42 20. Institute for Atmospheric and Climate Science, ETH Zurich, Zurich, Switzerland

43 21. Climate Analytics, 10961 Berlin, Germany

44 22. Environmental and Life Sciences, University of The Bahamas, Nassau 76905, The Bahamas

45 23. Tyndall Centre for Climate Change Research and School of Environmental Sciences, $46 \quad$ University of East Anglia, Norwich NR4 7TJ, UK

24. State Key Laboratory of Severe Weather, Chinese Academy of Meteorological Sciences, Beijing 100081, China

\section{Abstract (150 words):}

Global mean surface temperature is now $1.0^{\circ} \mathrm{C}$ higher than the pre-industrial period due to increasing atmospheric greenhouse gases. Significant changes to natural and human (managed) systems have already occurred emphasizing serious near-term risks. Here, we expand on the recent IPCC Special Report on global warming of $1.5^{\circ} \mathrm{C}$ as well as additional risks associated with dangerous and irreversible states at higher levels of warming, each having major implications for multiple geographies, climates and ecosystems. Limiting warming to $1.5^{\circ} \mathrm{C}$ rather than $2.0^{\circ} \mathrm{C}$ is very beneficial, maintaining significant proportions of systems such as Arctic

59 summer sea ice, forests and coral reefs as well as having clear benefits for human health and 60 economies. These conclusions are relevant for people everywhere, particularly in low- and 61 middle-income countries, where climate related risks to livelihoods, health, food, water, and

62 economic growth are escalating with major implications for the achievement of the United 63 Nations Sustainable Development Goals. 
64 One Sentence Summary: Climate change is already driving dangerous impacts that will be

65 progressively less manageable at $1.5^{\circ} \mathrm{C}$ of global warming or higher.

Main text:

67 Climate change is one of the greatest challenges for humanity. Global mean surface temperature

68 (GMST) is increasing at the rate of $0.2^{\circ} \mathrm{C} \pm 0.1^{\circ} \mathrm{C}$ per decade, reaching $1.0^{\circ} \mathrm{C}$ above the pre-

69 industrial period (reference period 1850-1900) in 2017 (1). GMST is projected to reach $1.5^{\circ} \mathrm{C}$

70 above the pre-industrial period between 2030 and 2052, depending on the model and

71 assumptions regarding projected changes to atmospheric greenhouse gas (GHG) levels and

72 climate sensitivity (1). At the same time, growing awareness of impacts beyond $1.5^{\circ} \mathrm{C}$ has

73 focused international attention on the feasibility and implications of stabilizing temperatures at

74 this level (2).

In broad terms, limiting warming to $1.5^{\circ} \mathrm{C}$ will require a total investment in the energy sector of 1.46-3.51 trillion (US\$2010) in energy supply and 0.64-0.91 trillion (US\$2010) in energy demand measures in order to reach net zero GHG emissions by 2050 (3)(p154). On the other hand, the mean net present value (in 2008) of the avoided damages resulting from this action is estimated as totalling \$496 trillion (US\$2010) by the year 2200 (3-5). This, together with other damages that are difficult to fully cost and include (e.g. disruption and migration of human communities; reductions in ecosystem services associated with biodiversity loss), suggests that potential economic benefits arising from limiting warming to $1.5^{\circ} \mathrm{C}$ may be four or five times larger than the investments needed to stabilize GMST to $1.5^{\circ} \mathrm{C}(\mathrm{SM} 1)(3)$.

Here, we explore the near-term mostly unmonetized impacts projected for $1.5^{\circ} \mathrm{C}$ of global warming, and the associated risks and adaptation options for natural and human (managed) systems. In order to understand the implications of reaching $1.5^{\circ} \mathrm{C}$, we compare it to recent conditions (i.e. $1.0^{\circ} \mathrm{C}$ warming above the pre-industrial period, Fig 1), and to those that are projected to emerge as we approach $2.0^{\circ} \mathrm{C}$ of warming. This comparison helps understand the

91 benefits or not of stabilizing GMST at $1.5^{\circ} \mathrm{C}$ as compared to $2.0^{\circ} \mathrm{C}$ or higher, as well as

92 providing a framework for societal responses and consequences. 
94 [Insert Figure 1 here]

95

96

97

98

99

100

101

102

103

104

105

106

107

108

109

110

\section{Crossing the $1.0^{\circ} \mathrm{C}$ threshold has already severely impacted natural and human systems}

The incidence of extremes has increased sharply as GMST has warmed from $0.5^{\circ} \mathrm{C}$ to $1.0^{\circ} \mathrm{C}$ $(\sim 1980-2018)$ relative to the Pre-industrial period, with the intensity and/or frequency of extremes projected to change further with another $0.5^{\circ} \mathrm{C}$ of warming (5). As GMST has increased, for example, the average temperature of cold days and nights (i.e. the coldest 10\%) has also increased overall, as has the average temperature of warm days and nights (i.e. the warmest 10\%) globally (5). These changes have also been accompanied by increases in the frequency and/or duration of heatwaves for large parts of Europe, North America and Australia. Increases in GMST have been accompanied by increases in the frequency, intensity and/or amount of heavy precipitation in more regions than those with decreases, especially in NorthHemisphere mid-latitude and high-latitude areas $(5,6)$. There is also evidence of increasing rainfall associated with recent tropical cyclones $(6,7)$ and increasingly heavy precipitation during storms in the Central Sahel $(8,9)$. The number of tropical cyclones has decreased, while the number of very intense cyclones has increased, for many areas (5). There is less confidence regarding trends in the length of drought, although a significant increasing trend has been detected in the Mediterranean region (particularly Southern Europe, North Africa and the nearEast) (10-12).

As on land, coastal and marine habitats have also experienced an increased frequency, intensity and duration of underwater heatwaves, with a threefold increase in the number of marine heatwave days globally since 1980 (13). The differential heating of the water column has also led to increased thermal stratification in some coastal and oceanic regions which decreases oceanatmosphere gas exchange as well the turnover of nutrients between the photic layer and deeper layers of the ocean. The annual mean Arctic sea ice extent decreased by $3.5-4.1 \%$ per annum from 1979 to 2012 (6). The melting of land-based ice includes potentially unstable regions such as the Western Antarctic Ice Sheet (WAIS, Fig 1B), which contributed $6.9 \pm 0.6 \mathrm{~mm}$ over 19792017 to global mean sea level (GMSL). Together with glacial melt water, thermal expansion of

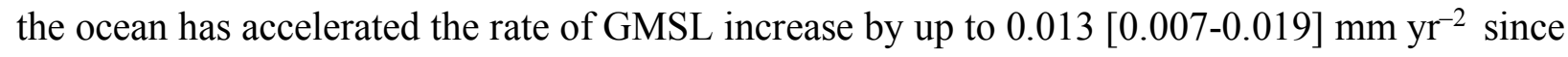


124 the early 20th Century (14). Changes in ocean temperature have also decreased the oxygen

125 concentration of the bulk ocean, interacting with coastal pollution to increase the number and

126 extent of low oxygen dead zones in many deep-water coastal habitats (15). In addition to

127 increasing GMST, anthropogenic $\mathrm{CO}_{2}$ also enters the ocean causing a reduction in $\mathrm{pH}$ (ocean

128 acidification) which negatively impacts processes such as early development, calcification,

129 photosynthesis, respiration, sensory systems, and gas exchange in organisms from algae to fish

130 (5).

132 Changing weather patterns (e.g. temperature, rainfall, dryness, storms) have increased negative

133 impacts on natural and managed systems (Fig 1A-D). Changes to coral reefs (5), forests (e.g.

134 changing drought/fire regimes) $(16,17)$, low-lying islands and coasts $(5)$, and impacts on

135 agriculture production and yield $(18,19)$ are threatening resources for dependent human

136 communities. There are also many gradual changes that have occurred as GMST has increased,

137 with many being no less important than the more abrupt changes. Land-based biomes (i.e. major

138 natural and agricultural ecosystem types) have also shifted to higher latitudes and elevation in

139 boreal, temperate and tropical regions $(5,15)$., with similar shifts reported for marine and

140 freshwater organisms. Marine organisms and some ecosystems have also shifted their

141 biogeographical ranges to higher latitudes at rates up to $40 \mathrm{~km} \mathrm{yr}^{-1}$. Rates are highest for pelagic

142 organisms and ecosystems such as plankton, and are lowest for more sedentary benthic

143 organisms and ecosystems such as seaweeds and kelp forests $(5,15)$. These types of changes

144 (e.g. temperature, storms, circulation) have also affected the structure and function of ocean

145 ecosystems with respect to its biodiversity, food-webs, incidence disease and invasive species

146 (5).

148 Other changes to biological systems include changes to the phenology of marine, freshwater and

149 terrestrial organisms (e.g. timing of key events such as reproduction and migration) $(5,15)$. The

150 phenology of plants and animals in the Northern-Hemisphere, for example, has advanced by 2.8

$151 \pm 0.35$ days per decade due to climate change, with similar changes in the flowering and

152 pollination of plants and crops, and the egg-laying and migration times of birds $(5,20)$. There are

153 indications that climate change has already contributed to observed declines in insects and

154 arthropods in some regions $(21,22)$. Variations in these types of changes have also been 
155 observed in the phenology of tropical forests, which have been more responsive to changes in

156 moisture stress rather than to the direct changes in temperature (5). While the intention here is

157 not to catalogue all of the changes that have occurring in natural systems, it is important to

158 acknowledge that deep and fundamental changes are underway in biological systems with just

$159 \quad 1^{\circ} \mathrm{C}$ of global warming so far (5).

160

161 Changes in GMST of $1.0^{\circ} \mathrm{C}$ have also directly and indirectly affected human communities, many

162 of which depend on natural and managed systems for food, clean water, coastal defence, safe

163 places to live, and livelihoods among many other ecosystem goods and services (5). Coral reefs

164 clearly illustrate the linkage between climate change, ecosystem services and human well-being.

165 At $1.0^{\circ} \mathrm{C}$, large-scale mortality events driven by lengthening marine heatwaves have already

166 reduced coral populations in many places (5), with prominent coral reef ecosystems such as the

167 Great Barrier Reef in Australia losing as much as 50\% of their shallow water corals in the last

168 four years alone $(5,23,24)$. These changes have potential implications for millions of people

169 given their dependency on coral reefs for food, livelihoods and well-being (5).

\section{Understanding climate change over the next few decades: methods and assumptions}

171

172 There are a range of strategies for quantifying risks for natural and human systems at $1.5^{\circ} \mathrm{C}$ and

$1732.0^{\circ} \mathrm{C}$ above the pre-industrial period. This requires calculating the future exposure of systems

174 to changes in climatic hazards. Some methods rely on the fact that an equivalent amount of

175 warming (e.g. $0.5^{\circ} \mathrm{C}$ ) occurred in the recent past (e.g. ca. 1950 to 2000, or ca. 1980 to 2018, Fig

$1762 \mathrm{~A}$; (3)) potentially providing insights into how risks might change in the near future. In this

177 case, the associated risks of the next $0.5^{\circ} \mathrm{C}$ of global warming (Fig 2A) are linearly extrapolated

178 from the impacts associated with the previous $0.5^{\circ} \mathrm{C}$ increase (ca. 1980-2018). This method of

179 projecting future risk is likely to be conservative given (a) the pace of climate change is

180 increasing (25) and (b) the impacts per unit of temperature are likely to increase as conditions are

181 pushed increasingly beyond the optimal conditions for a particular organism or physiological

182 process (Fig 2B)(26). Responses by natural and human systems are likely to also differ if

183 temperature pathways involve a gradual increase to $1.5^{\circ} \mathrm{C}$ above the pre-industrial period (no

184 'overshoot') as opposed to pathways that first exceed $1.5^{\circ} \mathrm{C}$ before later declining to $1.5^{\circ} \mathrm{C}$, 
185 which is referred to as an 'overshoot' (5) (Fig 2A). High levels of overshoot involve exceeding

$186 \quad 1.5^{\circ} \mathrm{C}$ by $0.1^{\circ} \mathrm{C}$ (Figure $\left.2 \mathrm{~A}\right)(3)$.

188 [Insert Figure 2 here]

190 Other approaches for understanding how the world may change at $1.5^{\circ} \mathrm{C}$ and $2.0^{\circ} \mathrm{C}$ of global

191 warming draw on laboratory, mesocosm, and field experiments. These approaches simulate

192 projected conditions for different levels of warming and, in the case of marine systems, levels of

193 acidification (e.g. changes in $\mathrm{pH}$, carbonate, pollution levels $(5,26,27)$. These experimental

194 approaches also provide calibration as well as insight into future conditions and responses (i.e.

$1951.5^{\circ} \mathrm{C}$ versus $2.0^{\circ} \mathrm{C}$ ). Some caution is also required given that global increases of $1.5^{\circ} \mathrm{C}$ or $2.0^{\circ} \mathrm{C}$

196 may involve a broad range of regional responses. This arises due to uncertainties in (for

197 example) the likelihood of overshoot, land-atmosphere interactions, biophysical effects of land

198 use changes, and interannual climate variability (28). Several lines of evidence for

199 understanding these complex problems include the analysis of the frequency and intensity of

200 extremes as well as projections based on existing climate simulations and empirical scaling

201 relationships for $1.5^{\circ} \mathrm{C}$ and $2.0^{\circ} \mathrm{C}$ of global warming (5). Lines of investigation may also include

202 dedicated experiments prescribing sea surface conditions consistent with these levels of

203 warming, as done in the HAPPI (Half a degree Additional warming, Prognosis and Projected

204 Impacts) project (5). Furthermore, fully-coupled climate model experiments can be achieved

205 using GHG forcing consistent with $1.5^{\circ} \mathrm{C}$ or $2.0^{\circ} \mathrm{C}$ scenarios (5). These multiple yet different

206 lines of evidence (above) underpin the development of qualitatively consistent results regarding

207 how temperature means and extremes could change at $1.5^{\circ} \mathrm{C}$ as compared to $2.0^{\circ} \mathrm{C}$ of global

208 warming.

\section{Projected changes in climate at $1.5^{\circ} \mathrm{C}$ versus $2.0^{\circ} \mathrm{C}$ of global warming}

211 Understanding the potential advantages of restraining global warming to $1.5^{\circ} \mathrm{C}$ requires an

212 understanding of the risks associated with the exposure of natural and human systems to climatic

213 hazards, and how they change at $1.5^{\circ} \mathrm{C}$ relative to $2.0^{\circ} \mathrm{C}(\mathrm{Fig} 3)(29)$. Increases of GMST to

$2141.5^{\circ} \mathrm{C}$ will further increase the intensity and frequency of hot days and nights, and decrease the 
215 intensity and frequency of cold days and nights (Fig 3 C.D.E). Warming trends are projected to 216 be highest over land, in particular for temperature extremes, with increases of up to $3^{\circ} \mathrm{C}$ in the 217 mid-latitude warm season and up to $4.5^{\circ} \mathrm{C}$ in cold seasons at high latitudes. These increases are 218 projected to be greater at $2.0^{\circ} \mathrm{C}$ of global warming, with increases of up to $4^{\circ} \mathrm{C}$ in the mid219 latitude warm season and up to $6^{\circ} \mathrm{C}$ in the high-latitude cold season (e.g. Fig 3 A.C.D.E.) (29).

220 Heatwaves on land, which are already increasing pressure on health and agricultural systems, are 221 projected to become more frequent and longer (Fig 3 C.D.).

223 There is considerable evidence that dryness will increase in some regions, especially the 224 Mediterranean as well as southern Africa (5, 30-32). Risks of drought, dryness and precipitation 225 deficits are projected to increase at $1.5^{\circ} \mathrm{C}$ and even further at $2.0^{\circ} \mathrm{C}$ for some regions relative to 226 the pre-industrial period $(\mathrm{Fig} 3 \mathrm{~B}, \mathrm{~F})(5,33)$. Recent studies also suggest similar projections for 227 the western Sahel and southern Africa, as well as the Amazon, north-eastern Brazil, and Central 228 Europe $(5,34)$. Projected trends in dryness are uncertain in several regions, however, and some 229 regions are projected to become wetter(Fig $3 \mathrm{~B}, \mathrm{~F})(5)$. Reaching GMST of $1.5^{\circ} \mathrm{C}$ and $2.0^{\circ} \mathrm{C}$, for 230 example, would lead to a successive increase in the frequency, intensity and/or amount of heavy 231 rainfall when averaged over global land area (Fig $3 \mathrm{~B}, \mathrm{~F})$. Global warming of $2.0^{\circ} \mathrm{C}$ versus $1.5^{\circ} \mathrm{C}$ 232 increases exposure to fluvial flood risk particularly at higher latitudes and in mountainous 233 regions, as well as in East Asia, China (35) and eastern North America overall (5). The 234 prevalence of subsequent intense wet and dry spells, in which a prolonged drought is 235 immediately followed by heavy precipitation at the same location (potentially leading to 236 flooding) or vice versa, is projected to be greater at $2.0^{\circ} \mathrm{C}$ global warming versus $1.5^{\circ} \mathrm{C}(36)$. 237 These large changes between coupled wet and dry conditions represent a major challenge for 238 adaptation as they will affect water quality and availability as well as increased soil erosion 239 along many coastal areas. Sea level rise can also amplify problems through damage to coastal 240 infrastructure and the salinization of water supplies for drinking and agriculture (5).

242 Relatively few studies have directly explored the effect of $1.5^{\circ} \mathrm{C}$ versus $2.0^{\circ} \mathrm{C}$ of global warming 243 on tropical cyclones (5). These studies consistently reveal a decrease in the global number of 244 tropical cyclones at $1.5^{\circ} \mathrm{C}$ vs $1.0^{\circ} \mathrm{C}$ of global warming, with further decreases under $2.0^{\circ} \mathrm{C}$ vs $2451.5^{\circ} \mathrm{C}$ of global warming. Simultaneously, very intense cyclones are likely to occur more 
246 frequently at $2.0^{\circ} \mathrm{C}$ vs $1.5^{\circ} \mathrm{C}$ of global warming, with associated increases in heavy rainfall and

247 damage, further emphasizing the advantages of not exceeding $1.5^{\circ} \mathrm{C}$ (5).

[Insert Figure 3 here]

251 Coastal and oceanic regions are also projected to increase in temperature as GMST increases to

$2521.5^{\circ} \mathrm{C}$, and further to $2.0^{\circ} \mathrm{C}$, above the pre-industrial period. Absolute rates of warming are only

253 slightly lower in the ocean than on land although the shallower spatial gradient of ocean

254 temperature will mean that the velocity of climate change may be higher in many regions of the

255 ocean $(5,37)$. Increases in ocean temperature associated with $1.5^{\circ} \mathrm{C}$ and $2.0^{\circ} \mathrm{C}$ of global warming

256 will increase the frequency and duration of marine heatwaves, as well as reducing the extent of

257 ocean mixing due to the greater thermal stratification of the water column $(13,15)$. Sea ice is

258 projected to continue to decrease in the Arctic, although restraining warming to $1.5^{\circ} \mathrm{C}$ will mean

259 an ice free Arctic summer will only occur every 100 years, while warming to $2.0^{\circ} \mathrm{C}$ above the

260 pre-industrial period will mean an ice free Arctic summer is likely to occur every 10 years by

$2612100(5,38)$. These and other models indicate that there will be no long-term consequences for

262 sea ice coverage in the Arctic (i.e. no hysteresis)if GMST is stabilised at or below $1.5^{\circ} \mathrm{C}(3)$.

\section{Impacts on ecosystems at $1.5^{\circ} \mathrm{C}$ versus $2.0^{\circ} \mathrm{C}$ of global warming}

266 Multiple lines of evidence (5) indicate that reaching and exceeding $1.5^{\circ} \mathrm{C}$ will further transform

267 both natural and human systems, leading to reduced ecosystem goods and services for humanity.

268 Importantly, risks for terrestrial and wetland ecosystems such as increasing coastal inundation,

269 fire intensity and frequency, extreme weather events, and the spread of invasive species and

270 diseases are lower at $1.5^{\circ} \mathrm{C}$ as compared to $2.0^{\circ} \mathrm{C}$ of global warming (5). In this regard, the

271 global terrestrial land area that is predicted to be affected by ecosystem transformations at $2.0^{\circ} \mathrm{C}$

$272(13 \%$, interquartile range $8-20 \%)$ is approximately halved at $1.5^{\circ} \mathrm{C}(4 \%$, interquartile range $2-$

273 7\%). Risks for natural and managed ecosystems are higher on drylands as compared to humid

274 lands (5). The number of species that are projected to lose at least half of their climatically

275 determined geographic range at $2.0^{\circ} \mathrm{C}$ of global warming $(18 \%$ of insects, $16 \%$ of plants, $8 \%$ of 
276 vertebrates) would be significantly reduced at global warming of $1.5^{\circ} \mathrm{C}$ (i.e. to $6 \%$ of insects, $8 \%$

277 of plants, and 4\% of vertebrates)(5). In this regard, species loss and associated risks of

278 extinction are much lower at $1.5^{\circ} \mathrm{C}$ than $2^{\circ} \mathrm{C}$. Tundra and boreal forests at high latitudes are

279 particularly at risk, with woody shrubs having already encroached on tundra, which will increase 280 with further warming (5). Constraining global warming to $1.5^{\circ} \mathrm{C}$ would reduce risks associated

281 with the thawing of an estimated 1.5-2.5 million $\mathrm{km}^{2}$ of permafrost (over centuries) compared to 282 the extent of thawing expected at $2.0^{\circ} \mathrm{C}(5)$.

284 Ecosystems in the ocean are also experiencing large-scale changes, with critical thresholds 285 projected to be increasingly exceeded at $1.5^{\circ} \mathrm{C}$ and higher global warming. Increasing water 286 temperatures are driving the relocation of many species (e.g. fish, plankton) while sedentary 287 organisms, such as kelp and corals, are relatively less able to move. In these cases, there are 288 multiple lines of evidence that indicate that $70-90 \%$ of warm water tropical corals present today 289 are at risk of being eliminated even if warming is restrained to $1.5^{\circ} \mathrm{C}$. Exceeding $2.0^{\circ} \mathrm{C}$ of global 290 warming will drive the loss of $99 \%$ of reef-building corals (5). These non-linear changes in 291 survivorship are a consequence of the increasing impact of changes as they move away from 292 optimal conditions (Fig 2B) (26). Impacts on oceanic ecosystems are expected to increase at 293 global warming of $1.5^{\circ} \mathrm{C}$ relative to today, with losses being far greater at $2.0^{\circ} \mathrm{C}$ of global 294 warming. Significant compound or secondary risks exist with respect to declining ocean 295 productivity, loss of coastal protection, damage to ecosystems, shifts of species to higher 296 latitudes, and the loss of fisheries productivity (particularly at low latitudes)(15). There is 297 substantial evidence that these changes to coastal risks will increasingly threaten the lives and 298 livelihoods of millions of people throughout the world (5).

\section{Increasing risks for human (managed) systems at $1.5^{\circ} \mathrm{C}$ and $2.0^{\circ} \mathrm{C}$ of global warming}

300 Many risks for society will increase as environmental conditions change. Water, for example, is 301 often central to the success or failure of human communities. The projected frequency and scale 302 of floods and droughts in some regions will be smaller under $1.5^{\circ} \mathrm{C}$ global warming as opposed 303 to $2^{\circ} \mathrm{C}$, with risks to water scarcity being greater at $2.0^{\circ} \mathrm{C}$ than at $1.5^{\circ} \mathrm{C}$ of global warming for 304 many regions (5). Salinization of freshwater resources on small islands and along low-lying 305 coastlines is a major risk that will become successively more important as sea levels rise, 
306 particularly as they will continue to increase even if temperatures stabilise. (5). Depending on 307 future socio-economic conditions, limiting warming to $1.5^{\circ} \mathrm{C}$ is projected to reduce the 308 proportion of the world's population exposed to climate induced water stress by up to $50 \%$ as 309 compared at $2^{\circ} \mathrm{C}(5)$, although there is considerable variability among regions as already 310 discussed. Most regions, including the Mediterranean and Caribbean regions, are projected to 311 experience significant benefits from restraining global warming to $1.5^{\circ} \mathrm{C}(39)$, although socio312 economic drivers are expected to play a dominant role relative to climate change for these 313 communities over the next $30-40$ years.

315 Limiting global warming to $1.5^{\circ} \mathrm{C}$ is projected to result in smaller reductions in the yield of 316 maize, rice, wheat and potentially other cereal crops than at $2.0^{\circ} \mathrm{C}$, particularly in sub-Saharan 317 Africa, Southeast Asia, and Central and South America (40-42). A loss of 7-10\% of rangeland 318 stock globally is also projected to occur at an increase of $2.0^{\circ} \mathrm{C}$ above the pre-industrial period, 319 which will have considerable economic consequences for many communities and regions. 320 Reduced food availability at $2.0^{\circ} \mathrm{C}$ as compared to $1.5^{\circ} \mathrm{C}$ of global warming is projected for 321 many regions including the Sahel, Southern Africa, the Mediterranean, Central Europe and the 322 Amazon. Few examples exist where crop yields are increasing and hence food security is at 323 increasing risk in many regions (41). Although food systems in future economic and trade 324 environments may provide important options for mitigating hunger risk and disadvantage (43, $32544)(5)$, assuming that solutions are found to the decline in the nutritional quality of major cereal crops from higher $\mathrm{CO}_{2}$ concentrations (5).

328 Food production from marine fisheries and aquaculture is of growing importance to global food 329 security but is facing increasing risks from ocean warming and ocean acidification (5). These 330 risks increase at $1.5^{\circ} \mathrm{C}$ of global warming and ocean acidification, and are projected to impact 331 key organisms such as finfish, corals, crustaceans and bivalves (e.g. oysters) especially at low 332 latitudes (5). Small-scale fisheries that depend on coastal ecosystems such as coral reefs, 333 seagrass, kelp forests and mangroves, are expected to face growing risks at $1.5^{\circ} \mathrm{C}$ of warming as 334 a result of the loss of habitat (5). Risks of impacts, and subsequent risks to food security, are 335 projected to become greater as global warming reaches $1.5^{\circ} \mathrm{C}(5,43,44)$ Tropical cyclones have major impacts on natural and human systems, and are projected to increase in intensity in many 
337 regions, with the damage exacerbated by rapid sea level rise $(14,45)$. The tropical cyclones in 338 the North Atlantic basin in 2017 had significant and widespread effects on the small islands of 339 Caribbean as well as the United States, resulting in many deaths, displacement of communities, 340 elevated rates of morbidity and mental health issues, as well as the long-term loss of electricity 341 generation and distribution. These impacts have resulted in significant economic damage, which 342 has exceeded the annual GDP of some small island developing States $(46,47)$.

344 Millions of people are already exposed to coastal flooding due to sea level rise and storms, 345 particularly in cities. Projections of sea level rise remain uncertain (5), and may include 346 significant non-linear responses, in part due to the contribution of land-based ice (48-50). Due to 347 the time lag between increased emissions and higher sea levels, differences in mitigation at $1.5^{\circ} \mathrm{C}$ 348 and $2.0^{\circ} \mathrm{C}$, are relatively small compared with the uncertainty in the projections at 2050 or even 349 2100. Small differences can, however, have big impacts: an increase of $0.1 \mathrm{~m}$ of sea level rise, for 350 example, will expose an additional 10 million people to flooding (5) particularly those living in 351 low-lying deltas and small islands $(5,51)$. Even with mitigation, adaptation remains essential, 352 particularly as multi-metre sea level rise remains possible over several centuries for higher levels 353 of temperature rise (5). Estimates of the net present value in 2008 of global aggregate damage 354 costs (which would be incurred by 2200 if global warming is limited to $2.0^{\circ} \mathrm{C}$ ) reach $\$ 69$ trillion 355 (5). Damages from sea level rise alone contributes several trillion of dollars per annum (52). The 356 net present value in 2008 of global aggregate damage costs associated with $1.5^{\circ} \mathrm{C}$ warming 357 which would be incurred by 2200 if global warming is limited to $1.5 \mathrm{C}$ are less than those at $3582.0^{\circ} \mathrm{C}$, with comparable estimates around $\$ 54$ trillion in total (5).

360 Warming of $1^{\circ} \mathrm{C}$ has increased the frequency and scale of impacts on human health through 361 changes to the intensity and frequency of heatwaves, droughts, floods and storms, as well as 362 impacts on food quantity and nutritional quality (through increasing $\mathrm{CO}_{2}$ concentrations) 363 resulting in undernutrition or malnutrition in some regions $(5,43,44)$. Multiple lines of evidence 364 indicate that any further increases in GMST could have negative consequences for human health, 365 mainly through the intensification of these risks $(5,53)$. Lower risks are projected at $1.5^{\circ} \mathrm{C}$ than $3662.0^{\circ} \mathrm{C}$ of global warming for heat-related morbidity and mortality, and for ozone-related 367 mortality if ozone precursor emissions remain high. Limiting global warming to $1.5^{\circ} \mathrm{C}$ would 
368 result in 420 million fewer people being frequently exposed to 'extreme heatwaves' (defined by 369 duration and intensity (54)) and about 65 million fewer people being exposed to 'exceptional' 370 heatwaves as compared to conditions at $2.0^{\circ} \mathrm{C}$ GMST warming (55). Human health will also be 371 affected by changes in the distribution and abundance of vector-borne diseases such as dengue 372 fever and malaria, which are projected to increase with warming of $1.5^{\circ} \mathrm{C}$ and further at $2.0^{\circ} \mathrm{C}$ in 373 most regions (5). Risks vary by human vulnerability, development pathways, and adaptation 374 effectiveness $(43,44,56)$. In some cases, human activities can lead to local amplification of heat 375 risks from urban heat island effects in large cities $(57,58)$. More specific impacts of, and solutions to, climate change on cities are provided elsewhere $(43,56)$

Global warming of $1.5^{\circ} \mathrm{C}$ will also affect human well-being through impacts on agriculture, industry and employment opportunities. For example, increased risks are projected for tourism in many countries, whereby changes in climate have the potential to affect the attractiveness and/or safety of destinations, particularly those dependent on seasonal tourism including sun, beach and snow sport destinations $(5,15)$. Businesses that have multiple locations or markets may reduce overall risk and vulnerability, although these options are likely to be reduced as stress and impacts increase in frequency and areal extent. Risks and adaptation options may lie in developing alternative business activities that are less dependent on environmental conditions. These risks become greater as warming increases to $2.0^{\circ} \mathrm{C}$ and pose serious challenges for a large number of countries dependent on tourism and related activities for national income (5).

Multiple lines of evidence also reveal that poverty and disadvantage are also correlated with warming to $1.0^{\circ} \mathrm{C}$ above pre-industrial period, with the projection of increasing risks as GMST

391 increases from $1.0^{\circ} \mathrm{C}$ (today) to $1.5^{\circ} \mathrm{C}$ and higher $(43,44)$. In this regard, out-migration from 392 agriculturally-dependent communities is positively correlated with global temperature although 393 our understanding of the links between human migration and further warming of $1.5^{\circ} \mathrm{C}$ and $3942.0^{\circ} \mathrm{C}$ is at an early stage (5). Similarly, risks to global aggregate economic growth due to 395 climate change impacts are projected to be lower at $1.5^{\circ} \mathrm{C}$ than $2.0^{\circ} \mathrm{C}$ by the end of the century 396 (5). The largest reduction in economic growth at $2.0^{\circ} \mathrm{C}$ compared to $1.5^{\circ} \mathrm{C}$ are projected for low397 and middle-income countries and regions (the African continent, Southeast Asia, India, Brazil and Mexico). Countries in the tropics and Southern Hemisphere subtropics, are projected to 


\section{Science}

399 experience the largest negative impacts on economic growth if global warming increases from $400 \quad 1.5^{\circ} \mathrm{C}$ to $2.0^{\circ} \mathrm{C}$ above the pre-industrial period $(5,43,44)$. The most perceptible impacts of 401 climate change are likely to occur in tropical regions as GMST increases to $1.5^{\circ} \mathrm{C}$ and eventually 402 to $2^{\circ} \mathrm{C}$ above the pre-industrial period (59).

404 Table 1 summarizes the emergence of potential climate change 'hotspots' (i.e. areas where risks 405 are large and growing rapidly) for a range of geographies and sectors (5). In all cases, these 406 vulnerable regions show increasing risks as warming approaches $1.5^{\circ} \mathrm{C}$ and higher. Not all 407 regions, however, face the same challenges. In the Arctic, for example, habitat loss is 408 paramount, while changing temperature and precipitation regimes represent primary risks in the 409 Mediterranean, Southern Africa, West Africa and the Sahel. These rapidly changing locations 410 represent interactions across climate systems, ecosystems and socio-economic human systems, 411 and are presented here to illustrate the extent to which risks can be avoided or reduced by 412 achieving the $1.5^{\circ} \mathrm{C}$ global warming goal (as opposed to $2.0^{\circ} \mathrm{C}$ ).

414 [Insert Table 1 here]

416 Trajectories toward hotspots can also involve significant non-linearities or tipping points.

417 Tipping points refer to critical thresholds in a system that result in rapid systemic change when 418 exceeded (5). The risks associated with $1.5^{\circ} \mathrm{C}$ or higher levels of global warming reveal 419 relatively low risks for tipping points at $2.0^{\circ} \mathrm{C}$ but a substantial and growing set of risks as global 420 temperature increases to $3^{\circ} \mathrm{C}$ or more above the pre-industrial (Table 2) (5). For example, 421 increasing GMST to $3^{\circ} \mathrm{C}$ above the pre-industrial period substantially increases the risk of 422 tipping points such as permafrost collapse, Arctic sea ice habitat loss, major reductions in crop 423 production in Africa as well as globally, and persistent heat stress that is driving sharp increases 424 in human morbidity and mortality (Table 2) (5).

426 [Insert Table 2 here] 


\section{Solutions: scalability, feasibility and ethics}

429

430 GMST will increase by $0.5^{\circ} \mathrm{C}$ between 2030 and 2052 and will multiply and intensify risks for 431 natural and human systems across different geographies, vulnerabilities, development pathways, 432 as well as adaptation and mitigation options $(1,43,44,56)$. To keep GMST to no more than $4331.5^{\circ} \mathrm{C}$ above the pre-industrial period, the international community will need to bring GHG 434 emissions to net zero by 2050 while adapting to the risks associated with an additional $0.5^{\circ} \mathrm{C}$ 435 being added to $\operatorname{GMST}(3,5)$ The impacts associated with limiting warming to $1.5^{\circ} \mathrm{C}$, however, 436 will be far less than those at $2.0^{\circ} \mathrm{C}$ or higher (Table 1,2$)$. Aiming to limit warming to $1.5^{\circ} \mathrm{C}$ is 437 now a human imperative if escalating risks of dangerous if not catastrophic tipping points and 438 climate change hotspots are to be avoided $(2,5)$.

An important conclusion of the IPCC special report on $1.5^{\circ} \mathrm{C}$ is that limiting GMST to $1.5^{\circ} \mathrm{C}$ or less is still possible $(3,60)$. This will require limiting GHG emissions to a budget of $420{\mathrm{Gt} \mathrm{CO}_{2}}$ for a $66 \%$ or higher probability of not exceeding $1.5^{\circ} \mathrm{C}(44)$. As global emissions are currently around $42 \mathrm{Gt}_{\mathrm{CO}_{2}}$ per year, pathways should bring $\mathrm{CO}_{2}$ emissions to net zero over the next few decades (i.e. phase out fossil fuel use) alongside a substantial reduction ( $\sim 35 \%$ relative to 2010$)$ in emissions of methane and black carbon over the same time scale (44). The current set of national voluntary emission reduction pledges (Nationally Determined Contributions or NDCs), however, will not achieve the goals of the Paris Agreement (2, 61), particularly when considering the land-use sector (62). Instead, GMST is projected to increase by $3-4^{\circ} \mathrm{C}$ above the pre-industrial period $(1,44)$, posing serious levels of risk for natural and human systems $(3,5$, 20).

The majority of pathways for achieving $1.5^{\circ} \mathrm{C}$ also require the carbon dioxide removal (CDR) from the atmosphere. Delays in bringing $\mathrm{CO}_{2}$ emissions to net zero over the next 20-30 years will also increase the likelihood of pathways that exceed $1.5^{\circ} \mathrm{C}$ (so-called 'overshoot' scenarios) and hence a greater reliance on net negative emissions after mid-century if GMST to return to $1.5^{\circ} \mathrm{C}$ (Fig 2A). Technologies designed to remove $\mathrm{CO}_{2}$ from the atmosphere are at an early stage of development, with many questions as to their feasibility and scalability (5). For example, bioenergy with carbon capture and storage (BECCS), afforestation and reforestation, blue carbon 
459 (i.e. carbon sequestration by marine ecosystems and processes), soil carbon sequestration, direct 460 capture, biochar (i.e. charcoal for burial in soils), and enhanced weathering, variously struggle 461 from issues such as feasibility, scalability, and acceptability. These strategies are potentially in 462 competition with each other. For example, BECCS would require approximately $18 \%$ of global 463 land to sequester $12 \mathrm{Gt} \mathrm{CO}_{2} / \mathrm{yr}$ (5). This requirement is likely, however, to drive an accelerating 464 the loss of primary forest and natural grassland which would increase GHG emissions (5). Early 465 emission reductions plus measures to conserve land carbon stocks may reduce these effects.

466 Policy options might limit the expansion of agriculture at the expense of natural ecosystems, 467 and/or safeguard agricultural productivity from reductions due to BECCS and/or biofuel 468 production (5).

There are CDR options, however, that do not rely as extensively on BECCS, but rather focus on afforestation and/or the restoration of natural ecosystems. It is feasible, for example, to limit

472 warming to $1.5^{\circ} \mathrm{C}$ using strategies such as changing diets and promoting afforestation to remove $473 \mathrm{CO}_{2}(3,5,43,44)$. Negative consequences of afforestation such as monoculture plantations on 474 local biodiversity might be countered by preferentially restoring natural ecosystems, re475 establishing the ability of native grasslands, peatlands, forests, mangroves, kelp forests, and 476 saltmarshes to sequester carbon. This creates a 'win-win' scenario in which both climate and 477 biodiversity benefit, contributing to SDG 15 'Life on Land': and hence, simultaneously making 478 an enormous contribution to the goals of both CBD and UNFCCC. Compatible with this idea is 479 the recent UN establishment of the 2020s as the 'Decade of Restoration', with the intention to 480 build a global resolve to conserve biodiversity, increase its resilience to climate change, and use 481 it to sequester up to a total of $26 \mathrm{GtC}(63)$.

483 Extensive adaptation to $1.5^{\circ} \mathrm{C}$ of global warming or higher will be very important, especially if 484 we have underestimated climate sensitivity. Developing socially-just and sustainable adaptation 485 responses will be increasingly necessary to help natural and human systems to prepare and 486 respond to rapid and complex changes in risk (43). The global adaptation stocktake instigated by 487 the Paris Agreement will help accountability through documentation and mechanisms that 488 inform enhancement at national levels $(64,65)$. It must also be acknowledged that there are 489 limits to adaptation for natural and human systems (66) and hence subsequent loss and damage 
490 (5, 67-69). For example, actions to restore ecosystems may not always be possible given 491 available resources and it may not be feasible to protect all coastal regions from erosion and loss 492 of land. These challenges mean that identifying, assessing, prioritizing and implementing 493 adaptation options are very important for reducing the overall vulnerability to increasing climate494 related risks as GMST increases. It has become increasingly clear that long-term solutions to 495 climate change must also reduce disadvantage and poverty. Consequently, the recent IPCC 496 Special Report pursued its findings in the context of 'strengthening the global response to the 497 threat of climate change, sustainable development, and efforts to eradicate poverty' (3). While previous reports recognized the importance of not aggravating disadvantage, few have 499 specifically focused on solutions that involve multiple elements of climate change, sustainable 500 development and poverty alleviation. For example, greater insights and knowledge are required 501 to understand how multiple Sustainable Development Goals (SDGs) interact with each other, 502 although many of these interactions are beneficially synergistic (70). Importantly, SDGs are far 503 more easily reached at $1.5^{\circ} \mathrm{C}$ versus $2.0^{\circ} \mathrm{C}$ or more of global warming (43).

The important issue of 'loss and damage' also highlights the inequity between nations that have 506 largely caused climate change (and have received the greatest benefits) and those who have not. 507 This inequity is particularly important for least developed countries (LDCs) and small island 508 developing States (SIDSs) that have contributed relatively little to global GHG emissions but 509 now face disproportionate risks and harm from climate change, even at $1.5^{\circ} \mathrm{C}(67-69,71)$. 510 UNESCO has also emphasized the importance of ethics within a non-binding Declaration of 511 Ethical Principles in Relation to Climate Change in 2017 (72). Specifically, this declaration 512 states that "decision-making based on science is critically important for meeting the mitigation 513 and adaptation challenges of a rapidly changing climate. Decisions should be based on, and 514 guided by, the best available knowledge from natural and social sciences including 515 interdisciplinary and transitionary science and by considering (as appropriate) local, traditional 516 and indigenous knowledge". These types of initiatives are especially important in the 517 development of policies and actions that avoid inequalities that arise through exclusion and 518 misinformation (61). A transformation toward climate-resilient and low-carbon societies needs to 519 be done in a way that addresses the issue of justice and equity, through ensuring that trade-offs and synergies are identified and actioned (43). 


\section{Science}

\section{Conclusion}

522 Warming of $1.0^{\circ} \mathrm{C}$ since the mid-20th century has fundamentally transformed our planet and its 523 natural systems. Multiple lines of evidence reveal that a $1.5^{\circ} \mathrm{C}$ world will entail larger risks to 524 both human and natural systems. The risks of a $2^{\circ} \mathrm{C}$ world are much greater. This places us at a 525 critical time in human history where proportionate action taken today will almost certainly 526 minimize the dangerous impacts of a changing climate for hundreds of millions of people.

527 Our preliminary estimates suggest that the benefits of avoided damage by the year 2200 may

528 exceed the costs of mitigation by a factor of four or five. Current NDCs for 2030 are insufficient 529 to drive this even if followed by 'very challenging increases in the scale and ambition of 530 mitigation after 2030' (44)(p 95), because models based on the current understanding of 531 economic and technical dynamics cannot identify how to reduce GHG emissions to net zero by 5322050 from the current NDC starting point in 2030. Rather, these ambitions are consistent with a

533 global warming level of $3-4^{\circ} \mathrm{C}$ which means that immediate and transformative action is required 534 between now and 2030 in order to greatly scale up current nationally stated plans for GHG 535 reductions. Strategies for responding to climate change must be scalable to the challenges of 536 climate change being faced today and into the future, while at the same time being feasible and 537 fair. Given the scope and threats associated with climate change, there is an increasing need for 538 large scale strategies such as the UN Climate Resilient Development Pathways (CRDP) or 539 'Green New Deal' (UNEP) if society is to avoid potentially catastrophic circumstances over the 540 next few decades. 


\section{References and Notes:}

543 1. M. R. Allen et al., in Framing and Context, In: Global warming of $1.5^{\circ} \mathrm{C}$. An IPCC

$544 \quad$ Special Report on the impacts of global warming of $1.5^{\circ} \mathrm{C}$ above pre-industrial levels and

545 related global greenhouse gas emission pathways, in the context of strengthening the

546 global response to the , V. Masson-Delmotte et al., Eds. (World Meteorological

547 Organization, Geneva, Switzerland, 2018).

2. UNFCCC, "Decision 1/CP.21 Adoption of the Paris Agreement" (Paris, France, 2015), (available at https:/unfccc.int/sites/default/files/resource/docs/2015/cop21/eng/10a01.pdf).

3. IPCC, in Global warming of $1.5^{\circ} \mathrm{C}$. An IPCC Special Report on the impacts of global warming of $1.5^{\circ} \mathrm{C}$ above pre-industrial levels and related global greenhouse gas emission pathways, in the context of strengthening the global response to the threat of climate change, J. B. R. Matthews, Ed. (World Meteorological Organization, Geneva, Switzerland, 2018).

4. C. Hope, "The Social Cost of CO2 from the PAGE09 Model.” (2011), , doi:10.2139/ssrn.1973863.

5. O. Hoegh-Guldberg et al., in Impacts of $1.5^{\circ} \mathrm{C}$ Global Warming on Natural and Human Systems In: Global warming of $1.5^{\circ} \mathrm{C}$. An IPCC Special Report on the impacts of global warming of $1.5^{\circ} \mathrm{C}$ above pre-industrial levels and related global greenhouse gas emission pathways, in the context of $s, \mathrm{~V}$. Masson-Delmotte et al., Eds. (World Meteorological Organization, Geneva, Switzerland, 2018).

6. IPCC, “Climate Change 2013: The Physical Science Basis. Working Group I Contribution to the Fifth Assessment Report of the Intergovernmental Panel on Climate Change" 2013), , doi:http://www.ipcc.ch/report/ar5/wg1/. 
567 7. M. D. Risser, M. F. Wehner, Geophys. Res. Lett., in press, doi:10.1002/2017GL075888.

568 8. G. Panthou, T. Vischel, T. Lebel, Recent trends in the regime of extreme rainfall in the 569 Central Sahel. Int. J. Climatol. (2014), doi:10.1002/joc.3984.

570 9. C. M. Taylor et al., Frequency of extreme Sahelian storms tripled since 1982 in satellite observations. Nature (2017), doi:10.1038/nature22069.

10. L. Gudmundsson, S. I. Seneviratne, X. Zhang, Anthropogenic climate change detected in European renewable freshwater resources. Nat. Clim. Chang. 7, 813-816 (2017).

11. S. Mathbout et al., Observed Changes in Daily Precipitation Extremes at Annual Timescale Over the Eastern Mediterranean During 1961-2012. Pure Appl. Geophys. 175, 3875-3890 (2018).

12. F. Raymond, P. Drobinski, A. Ullmann, P. Camberlin, Extreme dry spells over the Mediterranean Basin during the wet season: Assessment of HyMeX/Med-CORDEX regional climate simulations (1979-2009). Int. J. Climatol. 38, 3090-3105 (2018).

13. D. A. Smale et al., Marine heatwaves threaten global biodiversity and the provision of ecosystem services. Nat. Clim. Chang. (2019), , doi:10.1038/s41558-019-0412-1.

14. J. A. Church et al., in Climate Change 2013: The Physical Science Basis. Contribution of Working Group I to the Fifth Assessment Report of the Intergovernmental Panel on Climate Change, T. F. Stocker et al., Eds. (Cambridge University Press, Cambridge, United Kingdom and NewYork, NY, USA, 2013), pp. 1137-1216.

15. O. Hoegh-Guldberg et al., in Climate Change 2014: Impacts, Adaptation, and Vulnerability. Part B: Regional Aspects. Contribution of Working Group II to the Fifth Assessment Report of the Intergovernmental Panel on Climate Change, V. R. Barros et al., Eds. (Cambridge University Press, Cambridge, United Kingdom and New York, NY, 
USA, 2014), pp. 1655-1731.

591 16. Y. Yin, D. Ma, S. Wu, Climate change risk to forests in China associated with warming. 592 Sci. Rep. 8, 1-13 (2018).

593 17. M. Turco et al., Exacerbated fires in Mediterranean Europe due to anthropogenic warming 594 projected with non-stationary climate-fire models. Nat. Commun. 9, 1-9 (2018).

595 18. B. Sultan et al., Assessing climate change impacts on sorghum and millet yields in the Sudanian and Sahelian savannas of West Africa. Environ. Res. Lett. 8, 014040 (2013).

19. X. Ren, Y. Lu, B. C. O’Neill, M. Weitzel, Economic and biophysical impacts on agriculture under 1.5 degrees $\mathrm{C}$ and 2 degrees $\mathrm{C}$ warming. Environ. Res. Lett. 13 (2018), doi:10.1088/1748-9326/aae6a9.

20. IPCC, Climate Change 2013 - The Physical Science Basis (Cambridge, United Kingdom and New York, NY, USA, 2014).

B. C. Lister, A. Garcia, Climate-driven declines in arthropod abundance restructure a rainforest food web. Proc. Natl. Acad. Sci. U. S. A. 115, E10397-E10406 (2018).

22. B. Martay et al., An indicator highlights seasonal variation in the response of Lepidoptera communities to warming. Ecol. Indic. 68, 126-133 (2016). Barrier Reef. Ecology. 99, 501 (2018). Science (80-. ). 363, 128-129 (2019). 
611 26. H.-O. Pörtner, C. Bock, F. C. Mark, Oxygen- and capacity-limited thermal tolerance:

612 Bridging ecology and physiology. J. Exp. Biol. (2017), doi:10.1242/jeb.134585.

613 27. S. G. Dove et al., Future reef decalcification under a business-as-usual CO2 emission 614 scenario. Proc. Natl. Acad. Sci. 110, 15342-15347 (2013).

615 28. S. I. Seneviratne et al., The many possible climates from the Paris Agreement's aim of 1.5 $616 \quad{ }^{\circ} \mathrm{C}$ warming. Nature. 558, 41-49 (2018).

617 29. S. I. Seneviratne, M. G. Donat, A. J. Pitman, R. Knutti, R. L. Wilby, Allowable CO2 618 emissions based on regional and impact-related climate targets. Nature. 529, 477-83 $619 \quad$ (2016).

620 30. P. Greve, L. Gudmundsson, S. I. Seneviratne, Regional scaling of annual mean 621 precipitation and water availability with global temperature change. Earth Syst. Dyn. 9, $622 \quad 227-240$ (2018).

623 31. T. Ozturk, Z. P. Ceber, M. Türkeş, M. L. Kurnaz, Projections of climate change in the 624 Mediterranean Basin by using downscaled global climate model outputs. Int. J. Climatol. $625 \quad 35,4276-4292(2015)$.

626 32. S. D. Polade, A. Gershunov, D. R. Cayan, M. D. Dettinger, D. W. Pierce, Precipitation in 627 a warming world: Assessing projected hydro-climate changes in California and other 628 Mediterranean climate regions. Sci. Rep. 7, 10783 (2017).

629 33. G. Naumann et al., Global Changes in Drought Conditions Under Different Levels of 630 Warming. Geophys. Res. Lett. 45, 3285-3296 (2018).

631 34. W. Liu et al., Global Freshwater Availability Below Normal Conditions and Population 632 Impact Under 1.5 and 2 degrees C Stabilization Scenarios. Geophys. Res. Lett. 45, 9803$6339813(2018)$. 
634 35. L. Lin et al., Additional Intensification of Seasonal Heat and Flooding Extreme Over 635 China in a 2 degrees C Warmer World Compared to 1.5 degrees C. EARTHS Futur. 6, 968-978 (2018).

637

36. G. D. Madakumbura et al., Event-to-event intensification of the hydrologic cycle from $1.5^{\circ} \mathrm{C}$ to a $2^{\circ} \mathrm{C}$ warmer world. Sci. Rep. 9, 3483 (2019).

37. J. García Molinos, M. T. Burrows, E. S. Poloczanska, Ocean currents modify the coupling between climate change and biogeographical shifts. Sci. Rep. 7, 1332 (2017).

38. J. A. Screen, Arctic sea ice at 1.5 and $2{ }^{\circ}$ C. Nat. Clim. Chang. 8, 362-363 (2018).

39. K. B. Karnauskas et al., Freshwater Stress on Small Island Developing States: Population Projections and Aridity Changes at $1.5^{\circ} \mathrm{C}$ and $2^{\circ} \mathrm{C}$. Reg. Environ. Chang., 1-10 (2018).

40. A. C. Ruane, M. M. Phillips, C. Rosenzweig, Climate shifts within major agricultural seasons for +1.5 and $+2.0{ }^{\circ} \mathrm{C}$ worlds: HAPPI projections and AgMIP modeling scenarios. Agric. For. Meteorol. 259, 329-344 (2018).

41. B. Liu et al., Global wheat production with 1.5 and $2.0^{\circ} \mathrm{C}$ above pre-industrial warming. Glob. Chang. Biol. 25, 1428-1444 (2019).

42. K. Rhiney, A. Eitzinger, A. D. Farrell, S. D. Prager, Assessing the implications of a $1.5^{\circ} \mathrm{C}$ temperature limit for the Jamaican agriculture sector. Reg. Environ. Chang. 18, 23132327 (2018).

43. J. Roy et al., in Sustainable development, poverty eradication and reducing inequalities; In: Global warming of $1.5^{\circ} \mathrm{C}$. An IPCC Special Report on the impacts of global warming of $1.5^{\circ} \mathrm{C}$ above pre-industrial levels and related global greenhouse gas emission pathways, in the c, V. Masson-Delmotte et al., Eds. (World Meteorological Organization, Geneva, Switzerland, 2018). 
657 44. J. Rogelj et al., in Mitigation pathways compatible with $1.5^{\circ} \mathrm{C}$ in the context of sustainable 658

45. K. Bhatia et al., Projected Response of Tropical Cyclone Intensity and Intensification in a Global Climate Model. J. Clim. 31, 8281-8303 (2018).

46. J. M. Shultz, J. P. Kossin, C. Ettman, P. L. Kinney, S. Galea, The 2017 perfect storm season, climate change, and environmental injustice. Lancet Planet. Heal. 2, e370-e371 (2018).

47. J. M. Shultz et al., Risks, Health Consequences, and Response Challenges for SmallIsland-Based Populations: Observations From the 2017 Atlantic Hurricane Season. Disaster Med. Public Health Prep. 13, 5-17 (2019).

48. T. L. Edwards et al., Revisiting Antarctic ice loss due to marine ice-cliff instability. Nature. 566, 58-64 (2019). Ice Sheet to Regional Ice Shelf Collapse. Geophys. Res. Lett. 46, 1467-1475 (2019). Clim. Chang. 8, 1053-1061 (2018).

676 51. M. I. Vousdoukas et al., Global probabilistic projections of extreme sea levels show intensification of coastal flood hazard. Nat. Commun. (2018), doi:10.1038/s41467-01804692-w. 
under the sea level rise with warming of $1.5 \circ \mathrm{C}$ and $2 \circ \mathrm{C}$. Environ. Res. Lett. 13 (2018).

53. M. B. Sylla, A. Faye, F. Giorgi, A. Diedhiou, H. Kunstmann, Projected Heat Stress Under 1.5 degrees $\mathrm{C}$ and 2 degrees $\mathrm{C}$ Global Warming Scenarios Creates Unprecedented Discomfort for Humans in West Africa. EARTHS Futur. 6, 1029-1044 (2018).

54. S. Russo, J. Sillmann, E. M. Fischer, Top ten European heatwaves since 1950 and their occurrence in the coming decades. Environ. Res. Lett. 10, 124003 (2015).

55. A. Dosio, L. Mentaschi, E. M. Fischer, K. Wyser, Extreme heat waves under $1.5^{\circ} \mathrm{c}$ and 2 ${ }^{\circ} \mathrm{c}$ global warming. Environ. Res. Lett. (2018), doi:10.1088/1748-9326/aab827.

56. H. de Coninck et al., in Strengthening and implementing the global response. In: Global warming of $1.5^{\circ} \mathrm{C}$. An IPCC Special Report on the impacts of global warming of $1.5^{\circ} \mathrm{C}$ above pre-industrial levels and related global greenhouse gas emission pathways, in the context of strengthen, V. Masson-Delmotte et al., Eds. (World Meteorological Organization, Geneva, Switzerland, 2018).

57. J. Mika et al., Impact of $1.5 \mathrm{~K}$ global warming on urban air pollution and heat island with outlook on human health effects. Curr. Opin. Environ. Sustain. 30 (2018), pp. 151-159.

58. C. R. O'Lenick et al., Urban heat and air pollution: A framework for integrating population vulnerability and indoor exposure in health risk analyses. Sci. Total Environ. 660, 715-723 (2019).

59. A. D. King, L. J. Harrington, The Inequality of Climate Change From 1.5 to $2^{\circ} \mathrm{C}$ of Global Warming. Geophys. Res. Lett. 45, 5030-5033 (2018). warming. Nat. Commun. 10, 1-10 (2019). 
702 61. C. Brown, P. Alexander, A. Arneth, I. Holman, M. Rounsevell, Paris climate goals 703 challenged by time lags in the land system. Nat. Clim. Chang. in prep (2019), doi:10.1038/s41558-019-0400-5.

705

706

707

708

709

710

62. A. B. Harper et al., Land-use emissions play a critical role in land-based mitigation for Paris climate targets. Nat. Commun. 9 (2018), doi:10.1038/s41467-018-05340-z.

63. S. L. Lewis, C. E. Wheeler, E. T. A. Mitchard, A. Koch, Restoring natural forests is the best way to remove atmospheric carbon. Nature (2019), doi:10.1038/d41586-019-010268.

64. B. Craft, S. Fisher, Measuring the adaptation goal in the global stocktake of the Paris Agreement. Clim. Policy. 18, 1203-1209 (2018).

65. E. L. Tompkins, K. Vincent, R. J. Nicholls, N. Suckall, Documenting the state of adaptation for the global stocktake of the Paris Agreement. Wiley Interdiscip. Rev. Clim. Chang. 9, e545 (2018).

66. K. Dow et al., Limits to adaptation. Nat. Clim. Chang. 3, 305-307 (2013).

67. K. E. McNamara, G. Jackson, Loss and damage: A review of the literature and directions for future research. Wiley Interdiscip. Rev. Clim. Chang. 10, e564 (2019).

68. R. Mechler, L. M. Bouwer, T. Schinko, S. Surminski, J. Linnerooth-Bayer, Eds., Loss and Damage from Climate Change (Springer International Publishing, Cham, 2019; http://link.springer.com/10.1007/978-3-319-72026-5), Climate Risk Management, Policy and Governance.

69. E. Boyd, R. A. James, R. G. Jones, H. R. Young, F. E. L. Otto, A typology of loss and damage perspectives. Nat. Clim. Chang. 7, 723-729 (2017). 


\section{Science}

724 70. M. Nilsson et al., Mapping interactions between the sustainable development goals:

725 lessons learned and ways forward. Sustain. Sci. 13, 1489-1503 (2018).

726 71. A. Thomas, L. Benjamin, Management of loss and damage in small island developing 727 states: implications for a $1.5^{\circ} \mathrm{C}$ or warmer world. Reg. Environ. Chang. 18, 2369-2378 728 (2018).

729 72. UNESCO, "Declaration of Ethical Principles Climate Change” (2017), (available at 730 https://unesdoc.unesco.org/ark:/48223/pf0000260129).

731 73. R. Wartenburger et al., Changes in regional climate extremes as a function of global mean 732 temperature: an interactive plotting framework. Geosci. Model Dev. 10, 3609-3634 733 (2017).

734 74. UNFCCC, Paris Agreement - Status of Ratification | UNFCCC (2019), (available at 735 https://unfccc.int/process/the-paris-agreement/status-of-ratification). 


\section{Acknowledgments:}

745 The authors volunteered their time to produce this review plus the underlying IPCC Special 746 Report on the "Impacts of Global Warming of $1.5^{\circ} \mathrm{C}$ above Pre-Industrial Levels and Related 747 Global Greenhouse Gas Emission Pathways, in the Context of Strengthening the Global 748 Response to the Threat of Climate Change, Sustainable Development, and Efforts to Eradicate 749 Poverty" (3). They are grateful for the support provided by the Intergovernmental Panel on 750 Climate Change (IPCC), particularly that of the Technical Support Units for Working Groups I 751 and II, as well as the large number of Contributing Authors and Science Officers involved in the 752 IPCC Special Report (3). The findings, interpretations, and conclusions expressed in the work do 753 not necessarily reflect the views of The World Bank, its Board of Executive Directors, or the 754 governments they represent.

\section{Supplementary Materials online:}

Material and Methods

SM1: $\underline{\text { Calculation of benefits versus costs for stabilizing at } 1.5^{\circ} \mathrm{C} \text { versus } 3.7^{\circ} \mathrm{C}}$.

Damages avoided can be estimated as those that accumulate under no mitigation scenarios (e.g. $3.7^{\circ} \mathrm{C}$ by 2100 ), as compared to high mitigation scenarios in which GMST stabilizes at $1.5^{\circ} \mathrm{C}$. Using PAGE09 model outputs, these are mean total damages of \$550 Trillion (US\$2008) versus \$54 Trillion (US\$2008)(3,4) The investments in the energy system required for stabilizing at $1.5^{\circ} \mathrm{C}$ are the sum of the required annual investments on the energy supply and demand side provided by IPCC (2018) over a 34-year period 2016-2050, amounting to a total of \$2.1-4.42 Trillion (US\$2010) annually, or \$71-150 Trillion (US\$2010). Most of the mitigation costs accrue during the period ending in 2050 since this is the target date for net zero greenhouse gas emissions in IPCC scenarios limiting warming to $1.5^{\circ} \mathrm{C}$.

The ratio is consequently approximately \$496 Trillion (US\$2008; mean damage avoided but no mitigation costs) versus \$71-150 Trillion (US\$2010; mitigation costs only) which means that the avoided damage is three and seven-fold higher than the cost of restraining GMST to $1.5^{\circ} \mathrm{C}$. Total mitigation cost estimates (3) are used in this comparison, as they include the costs of mitigation 


\section{Science}

775 required to reach the NDCs and also the further measures required to limit warming to $1.5^{\circ} \mathrm{C}$,

776 including measures which are required after 2030. If all the mitigation costs were incurred at the

777 mid-point of 2016 to 2050, their NPV in 2008 would be about half of the \$71-150 trillion

778 USD2010 (i.e. an even higher benefit to cost ratio). Furthermore, damages could be higher than

779 estimated, for reasons already outlined in the main text.

780

781 We also provide a further explanation of why other cost estimates provided in (3) were not the 782 appropriate for use in the comparison. (3) also states that "Global model pathways limiting 783 global warming to $1.5^{\circ} \mathrm{C}$ are projected to involve the annual average investment needs in the 784 energy system of around 2.4 trillion US $\$ 2010$ between 2016 and 2035 " but as further costs could 785 arise after 2030, and the damage estimate calculation refers to the year 2200, this is not 786 appropriate to use for this comparison. (3) also provides an estimate of the costs of measures 787 which are additional to the countries' Nationally Determined Contributions (NDCs). Since these 788 NDCs correspond to a global warming level of approximately $3-4^{\circ} \mathrm{C}$, this figure is not suitable 789 for comparison with avoided damage costs that refer to a baseline level of warming of 3.66C.

790 The estimate of the additional costs is 150 billion to 1700 billion US $\$ 2010$ over the same time 791 period. 
MIAAAS

793 Table 1: Emergence and intensity of climate change 'hotspots' under different degrees of global warming (summary, updated, Table

7943.6 from Hoegh-Guldberg et al., 2018, see text in 3.5.4 (5) for supporting literature and discussion; not intended to be all inclusive).

795 Calibrated uncertainty language is as defined by the Intergovernmental Panel on Climate Change (3).

\begin{tabular}{|c|c|c|c|}
\hline $\begin{array}{l}\text { Region and/or } \\
\text { Phenomenon }\end{array}$ & Warming of $1.5^{\circ} \mathrm{C}$ or less & Warming of $1.5^{\circ} \mathrm{C}-2^{\circ} \mathrm{C}$ & Warming of up to $3^{\circ} \mathrm{C}$ \\
\hline Arctic sea ice & $\begin{array}{l}\text { Arctic summer sea ice is likely to be } \\
\text { maintained } \\
\text { Habitat losses for organisms such as } \\
\text { polar bears, whales, seals and sea } \\
\text { birds } \\
\underline{\text { Benefits for Arctic fisheries }}\end{array}$ & $\begin{array}{l}\text { The risk of an ice-free Arctic in summer is } \\
\text { about } 50 \% \text { or higher } \\
\text { Habitat losses for organisms such as polar } \\
\text { bears, whales, seals and sea birds may be } \\
\text { critical if summers are ice free. } \\
\text { Benefits for Arctic fisheries }\end{array}$ & $\begin{array}{l}\text { The Arctic is very likely to be ice free in } \\
\text { summer } \\
\text { Critical habitat losses for organisms such as } \\
\text { polar bears, whales, seals and sea birds } \\
\text { Benefits for Arctic fisheries }\end{array}$ \\
\hline $\begin{array}{l}\text { Arctic land } \\
\text { regions }\end{array}$ & $\begin{array}{l}\text { Cold extremes warm by a factor of } \\
\begin{array}{l}\text { 2-3, reaching up to } 4.5^{\circ} \mathrm{C} \text { (high } \\
\text { confidence) }\end{array} \\
\text { Biome shifts in the tundra and } \\
\text { permafrost deterioration are likely }\end{array}$ & $\begin{array}{l}\frac{\text { Cold extremes warm by as much as } 8^{\circ} \mathrm{C}}{\text { (high confidence) }} \text {. } \\
\text { Larger intrusions of trees and shrubs in the } \\
\text { tundra than under } 1.5^{\circ} \mathrm{C} \text { of warming are } \\
\text { likely; larger but constrained losses in } \\
\text { permafrost are likely }\end{array}$ & $\begin{array}{l}\text { Drastic regional warming is very likely } \\
\text { A collapse in permafrost may occur (low } \\
\text { confidence); a drastic biome shift from tundra } \\
\text { to boreal forest is possible (low confidence) }\end{array}$ \\
\hline Alpine regions & $\underline{\text { Severe shifts in biomes are likely }}$ & Even more severe shifts are likely & 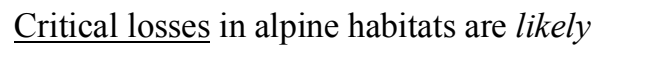 \\
\hline Southeast Asia & $\begin{array}{l}\text { Risks for increased flooding related } \\
\text { to sea level rise } \\
\text { Increases, heavy precipitation events } \\
\text { Significant risks of crop yield } \\
\text { reductions are avoided }\end{array}$ & $\begin{array}{l}\text { Higher risks of increased flooding related to } \\
\text { sea level rise (medium confidence) } \\
\text { Stronger increases, heavy precipitation } \\
\text { events (medium confidence) } \\
\text { One-third decline in per capita crop } \\
\text { production (medium confidence) }\end{array}$ & $\begin{array}{l}\text { Substantial increases in risks related to } \\
\text { flooding from sea level rise } \\
\frac{\text { Substantial increase in heavy precipitation and }}{\text { high-flow events }} \\
\underline{\text { Substantial reductions in crop yield }}\end{array}$ \\
\hline
\end{tabular}


AIAAAS

\begin{tabular}{|c|c|c|c|}
\hline Mediterranean & $\begin{array}{l}\text { Increase in probability of extreme } \\
\underline{\text { drought (medium confidence) }} \\
\frac{\text { Medium confidence in reduction in }}{\text { runoff of about } 9 \% \text { (likely range } 4.5-} \\
15.5 \% \text { ) } \\
\underline{\text { Risk of water deficit (medium }} \text { confidence) }\end{array}$ & $\begin{array}{l}\frac{\text { Robust increase in probability of extreme }}{\text { drought (medium confidence) }} \\
\frac{\text { Medium confidence in further reductions }}{\text { (about } 17 \% \text { ) in runoff (likely range } 8-28 \%)} \\
\text { Higher risks of water deficit (medium } \\
\text { confidence) }\end{array}$ & $\begin{array}{l}\text { Robust and large increases in extreme drought. } \\
\frac{\text { Substantial reductions in precipitation }}{\text { runoff (medium confidence) }} \text { and in } \\
\frac{\text { Very high risks of water deficit (medium }}{\text { confidence) }}\end{array}$ \\
\hline $\begin{array}{l}\text { West Africa \& } \\
\text { the Sahel }\end{array}$ & $\begin{array}{l}\text { Increases in the number of hot nights } \\
\text { and longer and more frequent } \\
\text { heatwaves are likely } \\
\text { Reduced maize and sorghum } \\
\text { production is likely, with area } \\
\text { suitable for maize production } \\
\text { reduced by as much as } 40 \% \\
\text { Increased risks of undernutrition }\end{array}$ & $\begin{array}{l}\text { Further increases in number of hot nights } \\
\text { and longer and more frequent heatwaves are } \\
\text { likely } \\
\text { Negative impacts on maize and sorghum } \\
\text { production likely larger than at } 1.5^{\circ} \mathrm{C} \text {; } \\
\text { medium confidence that vulnerabilities to } \\
\text { food security in the African Sahel will be } \\
\text { higher at } 2.0^{\circ} \mathrm{C} \text { compared to } 1.5^{\circ} \mathrm{C} \\
\text { Higher risks of undernutrition }\end{array}$ & $\begin{array}{l}\text { Substantial increases in the number of hot } \\
\text { nights and heatwave duration and frequency } \\
\text { (very likely) } \\
\text { Negative impacts on crop yield may result in } \\
\text { major regional food insecurities (medium } \\
\text { confidence) }\end{array}$ \\
\hline $\begin{array}{l}\text { Southern } \\
\text { Africa }\end{array}$ & $\begin{array}{l}\text { Reductions in water availability } \\
\text { (medium confidence) } \\
\text { Increases in number of hot nights and } \\
\text { longer and more frequent heatwaves } \\
\text { (high confidence), } \\
\text { High risks of increased mortality } \\
\text { from heatwaves } \\
\begin{array}{l}\text { High risk of undernutrition in } \\
\text { communities dependent on dryland } \\
\text { agriculture and livestock }\end{array}\end{array}$ & $\begin{array}{l}\text { Larger reductions in rainfall and water } \\
\text { availability (medium confidence) } \\
\text { Further increases in number of hot nights } \\
\text { and longer and more frequent heatwaves } \\
\text { (high confidence), associated increases in } \\
\text { risks of increased mortality from heatwaves } \\
\text { compared to } 1.5^{\circ} \mathrm{C} \text { warming (high } \\
\text { confidence) } \\
\text { Higher risks of undernutrition in } \\
\text { communities dependent on dryland } \\
\text { agriculture and livestock }\end{array}$ & $\begin{array}{l}\text { Large reductions in rainfall and water } \\
\text { availability (medium confidence) } \\
\text { Drastic increases in the number of hot nights, } \\
\text { hot days and heatwave duration and frequency } \\
\text { to impact substantially on agriculture, } \\
\text { livestock and human health and mortality } \\
\text { (high confidence) } \\
\text { Very high risks of undernutrition in } \\
\text { communities dependent on dryland agriculture } \\
\text { and livestock }\end{array}$ \\
\hline
\end{tabular}


М!AAAS

\begin{tabular}{|c|c|c|c|}
\hline Tropics & $\begin{array}{l}\text { Increases in the number of hot days } \\
\text { and hot nights as well as longer and } \\
\text { more frequent heatwaves (high } \\
\text { confidence) } \\
\text { Risks to tropical crop yields in West } \\
\text { Africa, Southeast Asia and Central } \\
\text { and South America are significantly } \\
\text { less than under } 2.0^{\circ} \mathrm{C} \text { of warming }\end{array}$ & $\begin{array}{l}\text { The largest increase in hot days under } 2.0^{\circ} \mathrm{C} \\
\text { compared to } 1.5^{\circ} \mathrm{C} \text { is projected for the } \\
\text { tropics. } \\
\text { Risks to tropical crop yields in West Africa, } \\
\text { Southeast Asia and Central and South } \\
\text { America could be extensive }\end{array}$ & $\begin{array}{l}\text { Oppressive temperatures and accumulated } \\
\text { heatwave duration very likely to directly } \\
\text { impact human health, mortality and } \\
\text { productivity } \\
\text { Substantial reductions in crop yield very likely }\end{array}$ \\
\hline Small islands & $\begin{array}{l}\text { Land of } 60,000 \text { less people exposed } \\
\text { by } 2150 \text { on SIDS compared to } \\
\text { impacts under } 2.0^{\circ} \mathrm{C} \text { of global } \\
\text { warming } \\
\text { Risks for coastal flooding reduced by } \\
20-80 \% \text { for SIDS compared to } 2.0^{\circ} \mathrm{C} \\
\text { of global warming } \\
\text { Freshwater stress reduced by } 25 \% \text { as } \\
\text { compared to } 2.0^{\circ} \mathrm{C}\end{array}$ & $\begin{array}{l}\text { Tens of thousands of people displaced owing } \\
\text { to inundation of SIDS } \\
\text { High risks for coastal flooding and increased } \\
\text { frequency of extreme water-level events } \\
\text { Freshwater stress from projected aridity } \\
\text { Further increase of ca. } 70 \text { warm days/year } \\
\text { Persistent heat stress in cattle in SIDS } \\
\text { Loss of most coral reefs and weaker } \\
\text { remaining structures owing to ocean } \\
\text { acidification (i.e. less coastal protection) }\end{array}$ & $\begin{array}{l}\text { Substantial and widespread impacts through } \\
\text { inundation of SIDS, coastal flooding, } \\
\text { freshwater stress, persistent heat stress and } \\
\text { loss of most coral reefs (very likely) } \\
\text { Risk of multi-meter sea level rise due to ice } \\
\text { sheet instability }\end{array}$ \\
\hline Fynbos biome & $\frac{\text { About } 30 \% \text { of suitable climate area }}{\text { lost }(\text { medium confidence })}$ & $\begin{array}{l}\text { Increased losses (about } 45 \%) \text { of suitable } \\
\text { climate area (medium confidence) }\end{array}$ & $\frac{\text { Up to } 80 \% \text { of suitable climate area lost }}{\text { (medium confidence) }}$ \\
\hline
\end{tabular}


MIAAAS

798 Table 2: Summary of enhanced risks in the exceedance of regional tipping points under different global temperature goals.

799 (summary, Table 3.7 from see text in 3.5.5(5), for supporting literature and discussion; updated, not intended to be exhaustive).

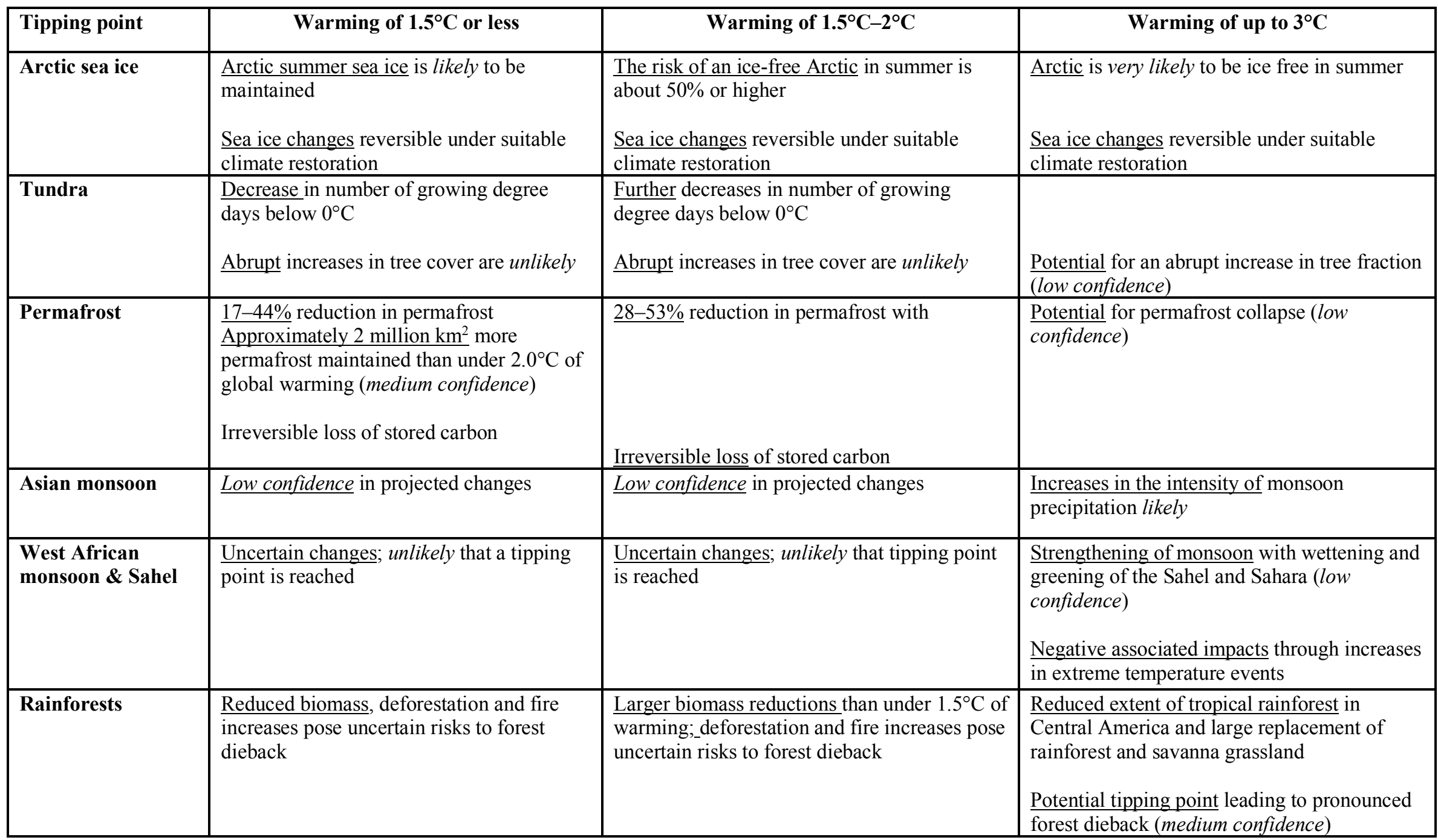


MIAAAS

\begin{tabular}{|c|c|c|c|}
\hline Coral reefs & $\begin{array}{l}\text { Increased mass coral bleaching and } \\
\text { mortality - decline in abundance to } 10-30 \% \\
\text { of values of present day by } 1.0^{\circ} \mathrm{C} \text { (high } \\
\text { confidence) }\end{array}$ & $\begin{array}{l}\text { High mortality - corals decrease to very low } \\
\text { levels }(<1 \%) \text { impacts on organisms that } \\
\text { dependent on coral reefs for habitat (fish, } \\
\text { biodiversity, high confidence). }\end{array}$ & $\begin{array}{l}\text { Irreversible changes occur with tipping point } \\
\text { around } 2^{\circ} \mathrm{C}-2.5^{\circ} \mathrm{C}-\text { reefs are no longer } \\
\text { resemble coral reef ecosystems - recovery } \\
\text { potential very low (medium confidence) }\end{array}$ \\
\hline Boreal forests & $\begin{array}{l}\text { Increased tree mortality at southern } \\
\text { boundary of boreal forest (medium } \\
\text { confidence) }\end{array}$ & $\begin{array}{l}\text { Further increases in tree mortality at southern } \\
\text { boundary of boreal forest (medium } \\
\text { confidence) }\end{array}$ & $\begin{array}{l}\text { Potential tipping point at } 3^{\circ} \mathrm{C}-4^{\circ} \mathrm{C} \text { for } \\
\text { significant dieback of boreal forest (low } \\
\text { confidence) }\end{array}$ \\
\hline $\begin{array}{l}\text { Heatwaves, } \\
\text { unprecedented heat } \\
\text { and human health }\end{array}$ & $\begin{array}{l}\text { Continued increase in occurrence of } \\
\text { potentially deadly heatwaves (likely) }\end{array}$ & $\begin{array}{l}\text { Substantial increase in potentially deadly } \\
\text { heatwaves (likely) } \\
\text { More than } 350 \text { million more people exposed } \\
\text { to deadly heat by } 2050 \text { under a midrange } \\
\text { population growth scenario (likely) } \\
\text { Annual occurrence of heatwaves similar to the } \\
\text { deadly } 2015 \text { heatwaves in India and Pakistan } \\
\text { (medium confidence) }\end{array}$ & $\begin{array}{l}\text { Further increases in potentially deadly } \\
\text { heatwaves (very likely) }\end{array}$ \\
\hline $\begin{array}{l}\text { Agricultural } \\
\text { systems: } \\
\text { key staple crops }\end{array}$ & Global maize crop reductions of about $10 \%$ & $\begin{array}{l}\text { Larger reductions in maize crop production } \\
\text { than under } 1.5^{\circ} \mathrm{C} \text { of about } 15 \%\end{array}$ & $\begin{array}{l}\text { Drastic reductions in maize crop globally and } \\
\text { in Africa (high confidence) potential tipping } \\
\text { point for collapse of maize crop in some } \\
\text { regions (low confidence) }\end{array}$ \\
\hline
\end{tabular}


802

AIAAAS

803 Figure 1. Changes at $1.0^{\circ} \mathrm{C}$ of global warming. Increases in Global Mean Surface Temperature

804 (GMST) of $1.0^{\circ} \mathrm{C}$ have already had major impacts on natural and human systems. Examples

805 include: A. Increased temperatures and dryness in the Mediterranean region is driving longer

806 and more intense fire seasons with serious impacts on people, infrastructure and natural

807 ecosystems. Image shows tragic devastation of fire in the Greek village of Mati Greece in July

808 25, 2018. B. Evidence of ice sheet disintegration is increasing (here showing a $30 \mathrm{~km}$ fracture

809 across the Pine Island Glacier which is associated with the Western Antarctic Ice sheet, WAIS).

810 The fracture (see arrow) appeared in mid-October 2011 and has increased concern that we may

811 be approaching a tipping point with respect to disintegration of the WAIS. C. Many low-lying

812 countries such as the Maldives experience flooding and will be at an increased threat from sea

813 level rise and strengthening storms over time. D. Many insects and birds have shifted

814 reproductive events or migration to early times in the season as conditions have warmed. Image

815 credits: A. 'Lotus R', https://www.flickr.com/photos/66012345@,N00/964251167; B. Image

816 credits: NASA/GSFC/METI/ERSDAC/JAROS and U.S./Japan ASTER Science TeamLast

817 Updated: Aug. 7, 2017, C. Male, Maldives (O. Hoegh-Guldberg) and D. Semipalmated Sand

818 Piper (Calidris pusilla, Creative Commons (CC BY-SA 3.0, GNU Free Documentation License)
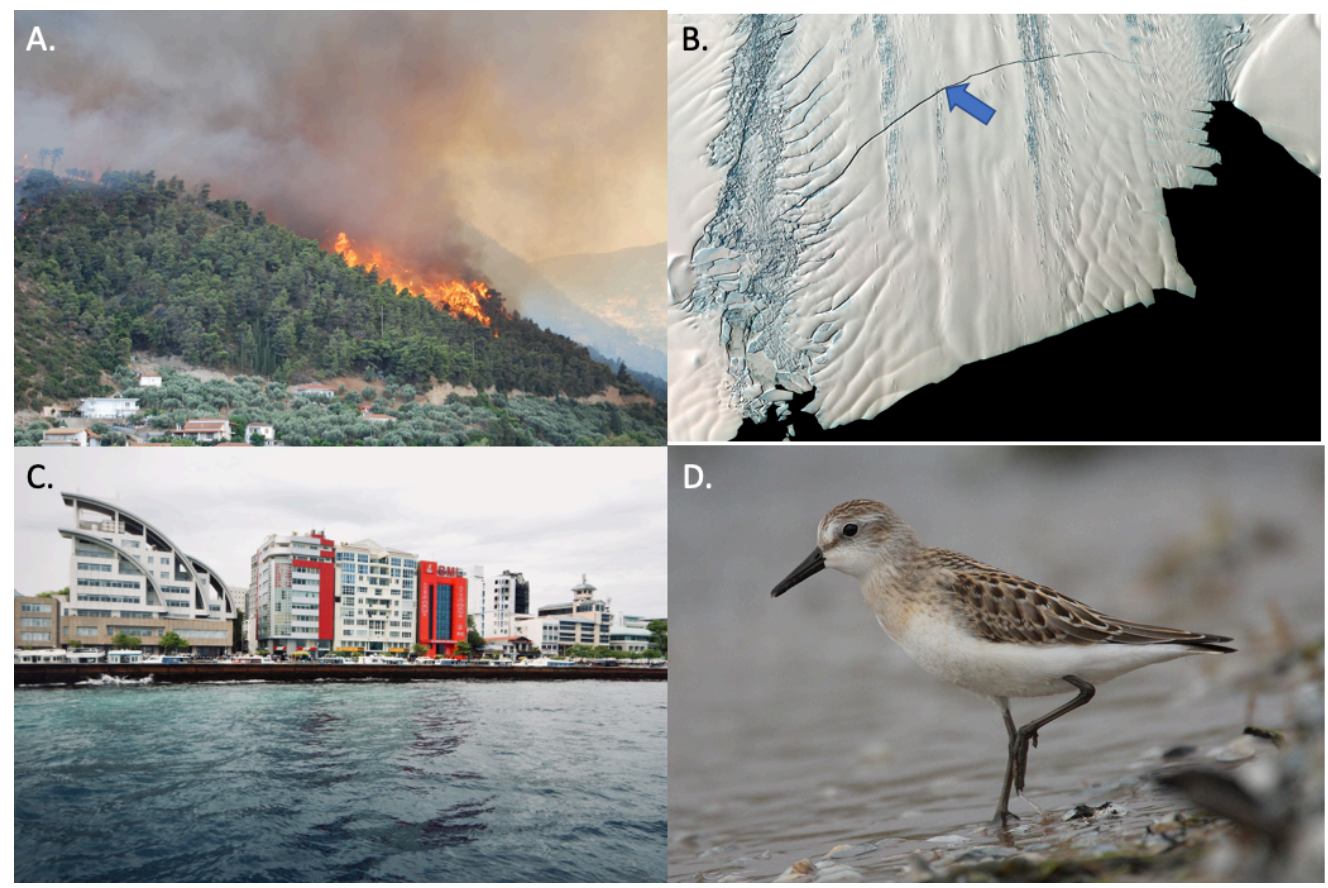


\section{Science}

820 Figure 2A. Action on climate change can still result in stable or even decreasing global 821 temperatures, although variability around projections is substantial. Strategies that include

822 'overshoot' (red dashed line, illustrative of a very high level of overshoot) require as yet early

823 stage technologies to ensure that overshoot is kept as short as possible. Also, the larger

824 overshoot, the higher the risk of irreversible change in affected systems. B. Responses to

825 changing conditions (shown here as a thermal performance curve) are typically tilted to the right

826 with a steep decline in performance such as growth, towards high temperature extremes. Beyond

827 a thermal optimum, Topt, performance begins to decline beyond the Pejus temperature, Tp. A

828 critical temperature, $T c$, characterizes a low level of performance and time limited passive

829 endurance when, as in ectothermic animals, oxygen supply capacity becomes insufficient to

830 cover oxygen supply, or, as in corals, a symbiosis between corals and their dinoflagellate

831 symbionts suddenly breaks down (coral bleaching) and corals go from appearing healthy to

832 experiencing large scale mortality over days-to-weeks. Accordingly, the high $T c$ characterizes a

833 temperature of high responsiveness to small increases in temperature extremes, such as by $0.5^{\circ} \mathrm{C}$,

834 especially, if some life stages have a narrow thermal range indicating high vulnerability(26). 
MIAAAS

A.

Overshoot

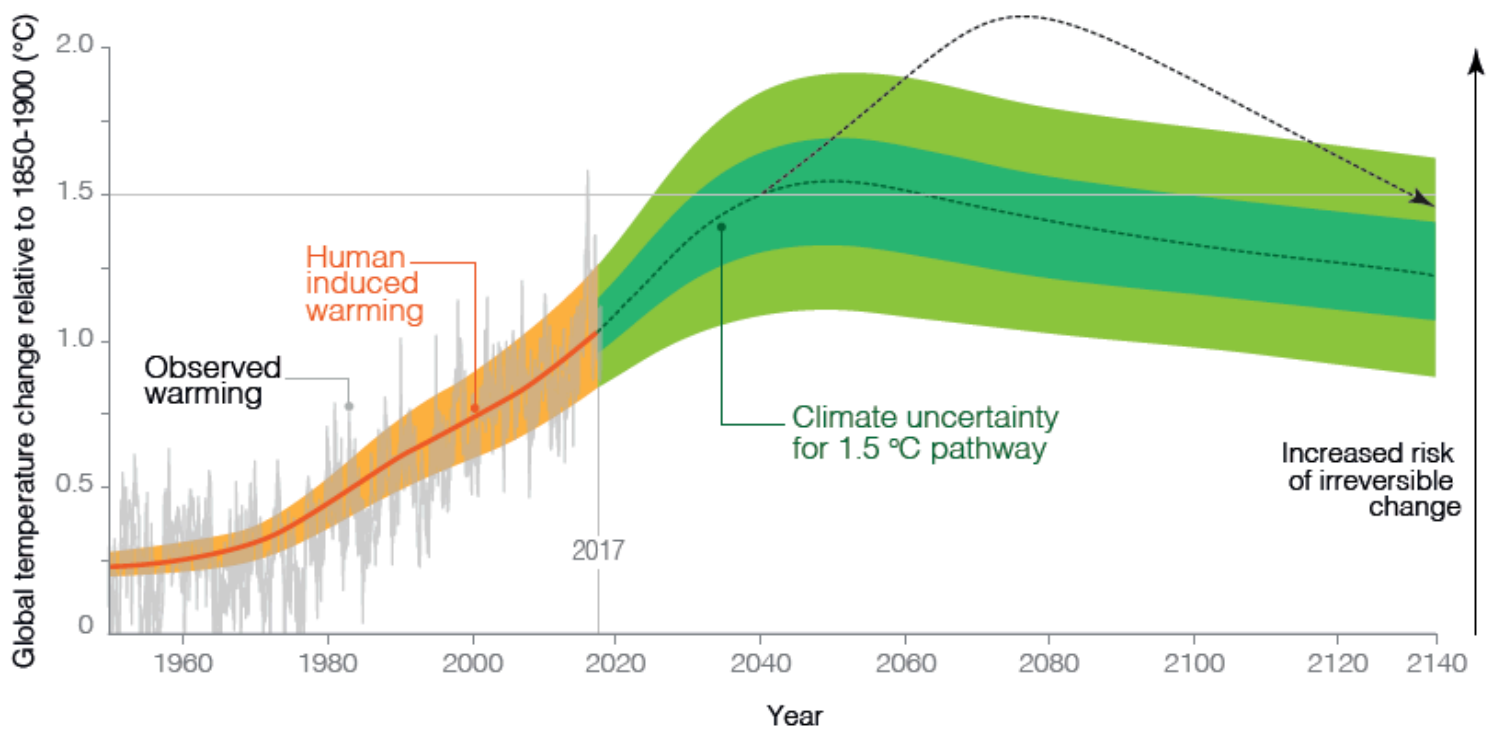

B.

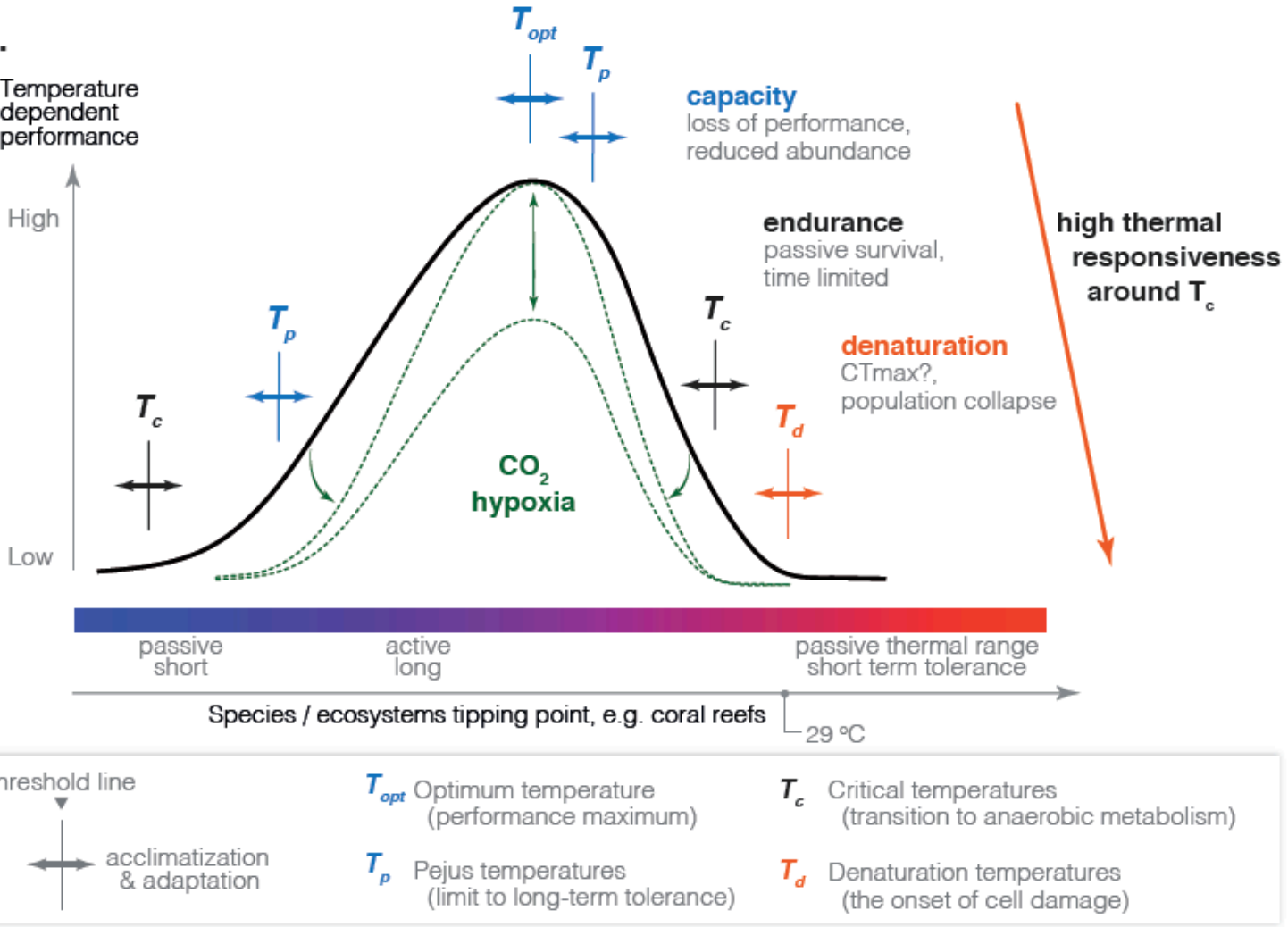




\section{Science}

838 Figure 3 Projected changes in A. Mean temperature, B. Mean precipitation, C. Number of hot 839 days (NHD; 10\% warmest days), D. Temperature of hottest day (TXx), E. Temperature of

840 coldest night (TNn), and F. Change in extreme precipitation (Rx5day). Conditions are projected

841 for $1.5^{\circ} \mathrm{C}$ (left-hand column) and $2.0^{\circ} \mathrm{C}$ (middle-hand column) of global warming compared to 842 the pre-industrial period (1861-1880), with the difference between $1.5^{\circ} \mathrm{C}$ and $2.0^{\circ} \mathrm{C}$ of global 843 warming being shown in the third column. Cross-hatching highlights areas where at least two844 thirds of the models agree on the sign of change as a measure of robustness (18 or more out of 845 26). Values were assessed from the transient response over a 10 -year period at a given warming 846 level, based on Representative Concentration Pathway (RCP) 8.5 Coupled Model

847 Intercomparison Project Phase 5 (CMIP5) model simulations (5)(3); adapted from (29, 73); see 848 Supplementary Material 3.SM.2 (5). 


\section{Science \\ MIAAAS}

\section{$850 \quad$ Figure 3}
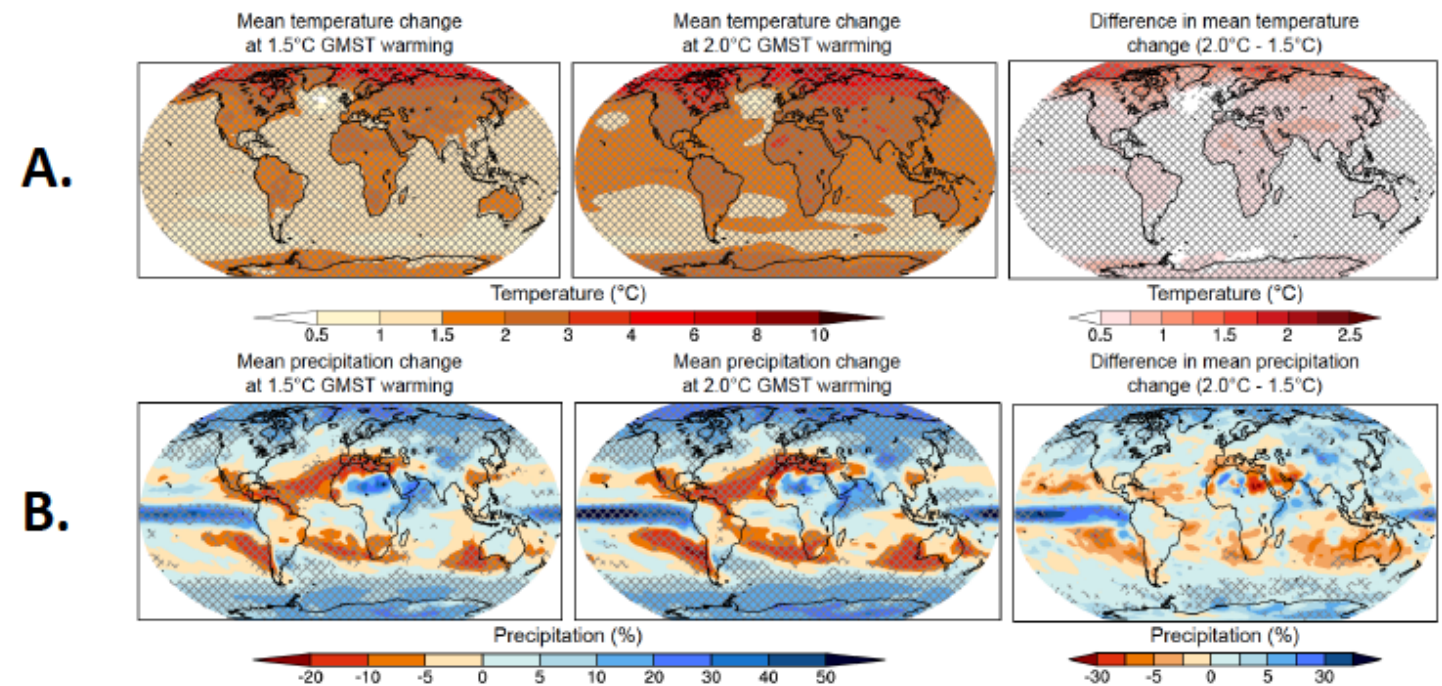

Change in number of hot days (NHD) at

Change in number of hot days (NHD) at

Difference in number of hot days
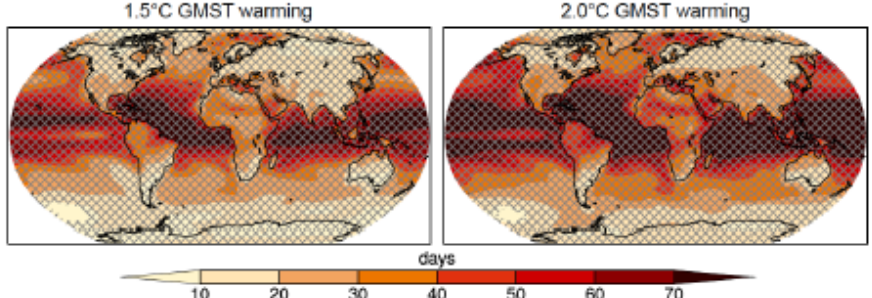

Change in temperature of hottest days ( $T$ XX) at $1.5^{\circ} \mathrm{C}$ GMST Warming

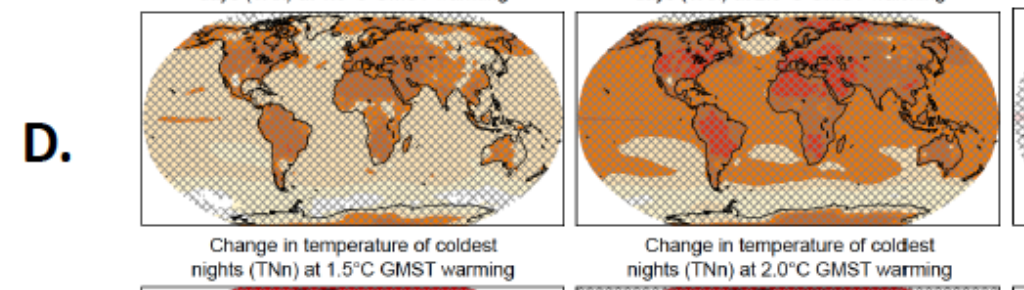

Change in temperature of coldest nights (TNn) at $1.5^{\circ} \mathrm{C}$ GMST warming
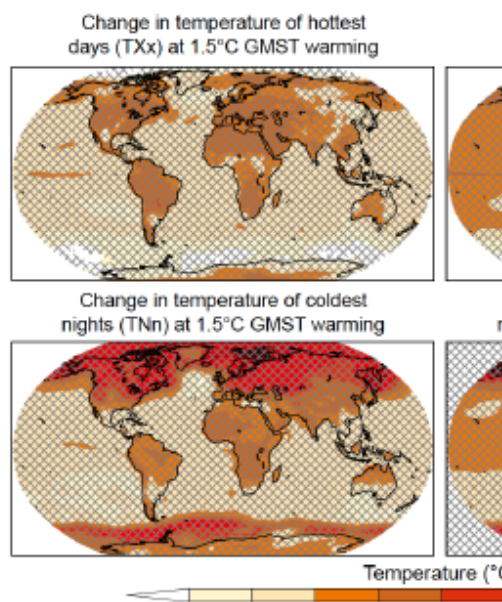

Change in temperature of hottest days (TXx) at $2.0^{\circ} \mathrm{C}$ GMST warming

E. nights (TNn) at $2.0^{\circ} \mathrm{C}$ GMST warming

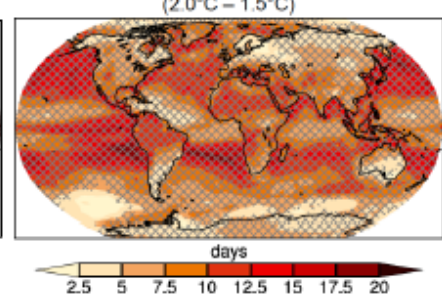

Difference in temperature of hottest days $(\mathrm{TXx})\left(2.0^{\circ} \mathrm{C}-1.5^{\circ} \mathrm{C}\right)$

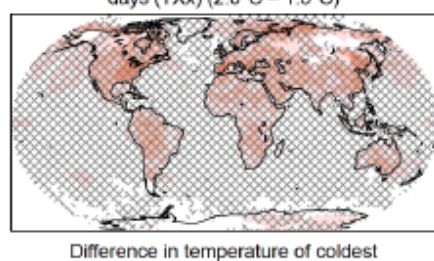

Difference in temperature of coldes

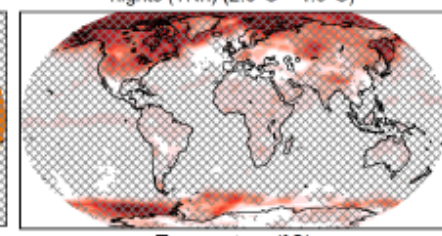

$$
\begin{array}{l|llllllll}
\hline & & & & & & & \\
0.5 & 1 & 1.5 & 2 & 3 & 4 & 6 & 8 & 10
\end{array}
$$

Change in extreme precipitation (Rx5day) at $1.5^{\circ} \mathrm{C}$ GMST warming Change in extreme precipitation

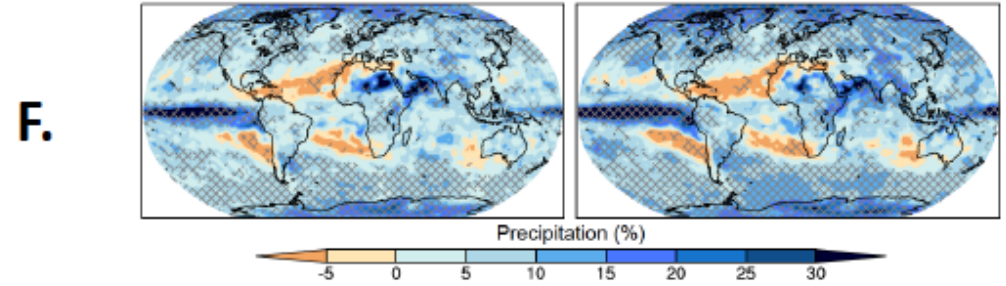
(Rxsday) at $2.0^{\circ} \mathrm{C}$ GMST warming

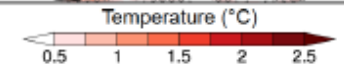

Difference in change in extreme precipitation (Rx5day) $\left(2.0^{\circ} \mathrm{C}-1.5^{\circ} \mathrm{C}\right)$

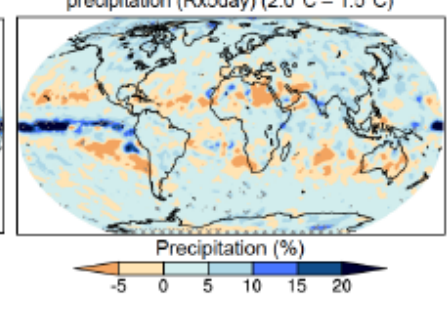


855 Summary of Review

\section{Background:}

860

United Nations Framework Convention on Climate Change (UNFCCC) was established in 1992 with the central purpose to pursue the "stabilization of greenhouse gas (GHG) emissions at a

862 level that would prevent dangerous anthropogenic interferences with the climate system". Since 863 1992, five major climate assessment reports have been completed by the UN Intergovernmental

864 Panel on Climate Change (IPCC). These reports identified rapidly growing climate related 865 impacts and risks, including more intense storms, collapsing ecosystems, and record heatwaves, among many others. Once thought to be tolerable, increases in global mean surface temperature (GMST) of $2.0^{\circ} \mathrm{C}$ or higher than the pre-industrial period look increasingly unmanageable and 868 hence dangerous to natural and human systems.

The Paris Climate Agreement is the most recent attempt to establish international cooperation over climate change (2). This agreement was designed to bring nations together voluntarily in order for them to take ambitious action on mitigating climate change while also developing adaptation options and strategies, and guaranteeing the means of implementation (e.g. climate

874 finance). Since that time, 185 countries have ratified the Agreement, including countries such as diverse as USA, Saudi Arabia and China (74). The Agreement is aimed at "holding the increase in the global average temperature to well below $2.0^{\circ} \mathrm{C}$ above pre-industrial levels and pursuing

877 efforts to limit the temperature increase to $1.5^{\circ} \mathrm{C}$ above pre-industrial levels, recognizing that 878 this would significantly reduce the risks and impacts of climate change." Many unanswered 879 questions regarding a $1.5^{\circ} \mathrm{C}$ target surround the feasibility, costs, and inherent risks to natural and 880 human systems. Consequently, the UNFCCC invited the IPCC to prepare a special report on the 881 "the impacts of global warming of $1.5^{\circ} \mathrm{C}$ above pre-industrial levels and related global 882 greenhouse gas emission pathways, in the context of strengthening the global response to the 883 threat of climate change, sustainable development, and efforts to eradicate poverty." The Special 884 Report was completed and approved by the $48^{\text {th }}$ Session of the IPCC in October 2018. 
MIAAS

886 Advances:

887 We review multiple lines of evidence that indicate that the next $0.5^{\circ} \mathrm{C}$ above today (which will 888 take GMST from $1.0^{\circ} \mathrm{C}$ to $1.5^{\circ} \mathrm{C}$ above the pre-industrial period) will involve greater risks per 889 unit temperature than those seen in the last $0.5^{\circ} \mathrm{C}$ increase. This principle of 'accelerating risk' is 890 also likely to drive proportionally higher risk levels in the transition from $1.5^{\circ} \mathrm{C}$ to $2.0^{\circ} \mathrm{C}$ above 891 the pre-industrial period. We argue that this is a consequence of impacts accelerating as a 892 function of distance from the optimal temperature (Top, Fig 2b) for an organism or process.

893 Ecosystems like coral reefs (Fig 1), for example, often appear healthy right up until the onset of 894 mass coral bleaching and mortality (Fig 2A,B), which can then rapidly destroy a coral reef 895 within a few months. This also explains the observation of 'tipping points' where the condition 896 of a group of organisms or an ecosystem can appear 'healthy' right up until they collapse,

897 suggesting caution in extrapolating from measures of ecosystem condition (i.e. changes in the 898 amount of coral cover). Information of this nature needs to be combined with an appreciation of 899 where organisms are with respect to the optimal temperature (Top, see Fig 2, Hoegh-Guldberg et 900 al. 2019, this issue).
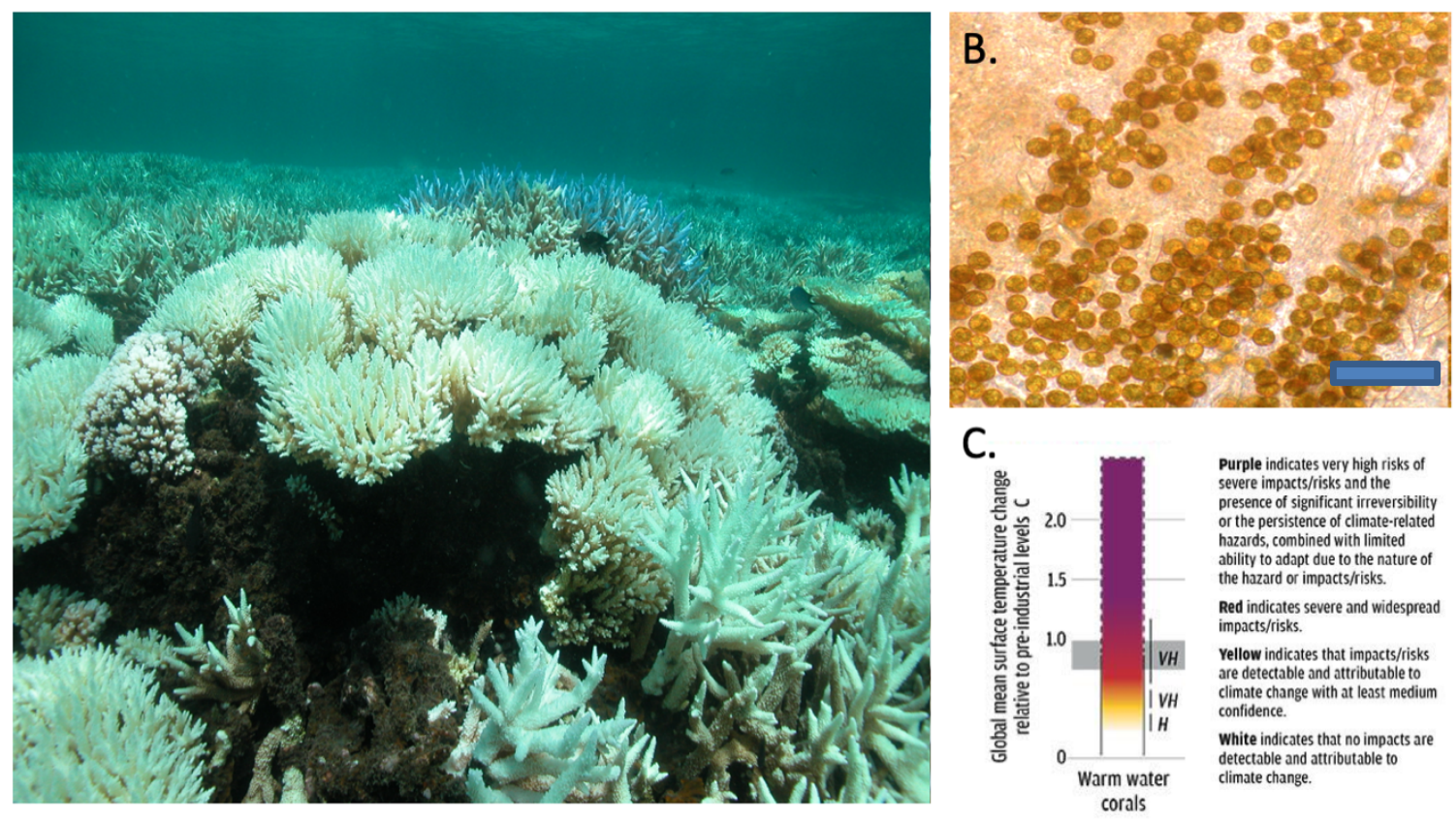

902 Fig 1 (legend). Responses to climate change can be non-linear in nature, such exemplified by

903 coral reefs. (A) Reef-building corals can suddenly lose their (B) dinoflagellate symbionts

904 (bar $=50 \mu \mathrm{m})$ and die in response to increasing temperatures, exhibiting (C) non-linear changes in 905 the amount of impact/risk from climate change. Attribution: A. Author, Hoegh-Guldberg ; B. 


\section{Science}

906 Author, Hoegh-Guldberg; $C$ is adapted from (5), $H$ (high) and VH (very high) are the levels of

907 confidence in the transition from one impact/risk level to another (i.e. colors).

908

909 In a similar way, human systems tend to experience greater costs and risks as we move away 910 from optimal conditions, with an increasing risk of non-linear changes. Finally, we explore the

911 relative costs and benefits associated with acting when it comes to climate change, and come to

912 the preliminary conclusion that restraining average global temperature to $1.5^{\circ} \mathrm{C}$ above the pre-

913 industrial period may be 4-5 less costly than the damage due to inaction on global climate

914 change.

915

\section{Outlook:}

917 As an IPCC expert group, we were asked to assess the impact of recent climate change $\left(1.0^{\circ} \mathrm{C}\right.$, 918 2017) and that likely over the next $0.5-1.0^{\circ} \mathrm{C}$ of global warming. At the beginning of this

919 exercise, many of us were concerned that the task would be hindered by a lack of expert

920 literature available for $1.5^{\circ} \mathrm{C}$ and $2.0^{\circ} \mathrm{C}$ warmer worlds. While this was the case at the time of the 921 Paris Agreement in 2015, it has not our experience four years later. With an accelerating amount 922 of peer-reviewed literature since the IPCC Special Report on $1.5^{\circ} \mathrm{C}$, it is very clear that there is 923 an even more compelling case for deepening commitment and actions for stabilizing global mean 924 surface temperature at $1.5^{\circ} \mathrm{C}$ above the pre-industrial period. 